\title{
Desarrollo, subdesarrollo y migraciones internacionales a comienzos del siglo $\mathrm{XXI}$
}

\author{
Javier Colomo Ugarte *
}

\begin{abstract}
RESUMEN ABSTRACT
Las migraciones internacionales se han

International migrations have often

tratado a veces de enjuiciar bajo However each historical moment is di criterios generales, pero cada momento histórico es diferente y a cada uno de ellos responde un tipo de migración. La explicación de los movimientos migratorios mundiales que emergen a finales del siglo $x x$ de los paises pobres al centro desarrollado tienen su origen en los profundos desequilibrios de los países del Tercer

Mundo. No responden, pues, a un proceso histórico coyuntural, sino que son consecuencia de graves problemas de carácter estructural. of that moment. The worldwide migrat poor countries to developed ones hay in these poor countries. They are th moment, but of deep structural probl The solution to this problem (if any and needs a longer one for it to be been analysed using general criferia fferent and each migration is a result: ions at the end of the 2Oth century from re their roots in the huge imbalances of ie result, not of a specific historical ems that these countries are victims of. $t)$ is not possible over a short period solved.
\end{abstract}

\section{INTRODUCCIÓN}

El origen de las migraciones del siglo xxı poco tiene que ver con el de las acontecidas en otros momentos de la historia contemporánea. Durante el siglo XIX, la expansión de la economía tuvo dos grandes flujos migratorios; por un lado, desde las metrópolis hacia las colonias o áreas de influencia de

* Doctor en Geografía. 
los países europeos, destacando América Latina, Oceanía y África como destinos de los europeos; por otro, la articulación del centro económico norteamericano atrajo también numerosa mano de obra principalmente europea. La migración transoceánica se desarrolló paralelamente a la dinámica económica cíclica de las metrópolis, de tal manera que fue máxima hasta los años veinte del siglo xx y descendió a raíz de la Gran Depresión.

Después de la Segunda Guerra Mundial, el auge en el centro y norte de Europa Occidental atrajo a varios millones de emigrantes del entonces sur semidesarrollado europeo-asiático (Portugal, España, Italia, Yugoslavia, Grecia, Turquía), que buscaron empleo en los sectores más significativos de la industrialización; la crisis económica de la segunda mitad de los setenta supuso el regreso de muchos emigrantes (especialmente españoles, italianos y portugueses), reduciéndose así la presencia extranjera perteneciente a paises europeos.

Desde la perspectiva mundial, la nueva fase de migración internacional comenzó a partir de los años cincuenta; los flujos migratorios han cambiado de sentido y, a partir de entonces, se producen mayoritariamente desde los países pobres hacia el centro desarrollado. Ello fue especialmente significativo en Estados Unidos, con flujos de inmigrantes procedentes de América Latina. El mismo fenómeno se produjo también en Europa, donde los inmigrantes de los países subdesarrollados se establecieron de forma estable, caso de los asiáticos y caribeños en Gran Bretaña o de los magrebíes y del África negra en Francia. De todas maneras, el inicio de la migración de las zonas subdesarrolladas al centro desarrollado en los años cincuenta y sesenta tuvo su origen, en el caso de Gran Bretaña y Francia, en los procesos de descolonización y, en el caso de Estados Unidos, en los profundos desequilibrios que vivía América Latina en los años sesenta y setenta, respondiendo, pues, a una situación histórica coyuntural. La emigración a estas zonas debiera haber remitido, si se hubieran cumplido las expectativas de desarrollo en los países de procedencia; pero ello no ha sido así $\mathrm{y}$, a finales del siglo $\mathrm{xx}$, la emigración al centro desarrollado desde los países subdesarrollados se ha incrementado notablemente. La pobreza y el subdesarrollo son la realidad que, cada vez con más fuerza, conforma el origen de las migraciones internacionales del siglo XXI.

\section{CAUSAS DE LOS MOVIMIENTOS MIGRATORIOS Y CAMBIOS DE TENDENCIA}

No existe una teoría general sobre las causas de las migraciones económicas. Esta carencia no es tanto por la falta de estudios sobre las mismas 
como porque éstas están sujetas a situaciones históricas cambiantes, por lo que hablar de causas de los fenómenos migratorios es hablar de causas en un contexto histórico determinado. Las causas de las migraciones se han venido tratando desde que en el siglo XIX se comenzaran a realizar estudios sobre las mismas. Las leyes de Ravenstein, formuladas en el siglo $x \mid x$, se pensaron para sociedades en transformación, desde un modelo de empleo mayoritariamente agricola a otro nuevo mayoritariamente industrial ${ }^{1}$. Según la doctrina económica neoclásica, la migración es una consecuencia de las diferencias de renta per cápita entre los distintos paises. Pero estas diferencias han existido entre países ricos y pobres desde la época colonial $y$, sin embargo, no es hasta finales del siglo $x x$ cuando cobran importancia las migraciones desde los países pobres al centro desarrollado.

Otras teorías afirman que el elevado crecimiento demográfico de los países produce un excedente de mano de obra que no puede ser absorbido de manera productiva y se traduce en migraciones más numerosas a los países desarrollados. Sin embargo, las pruebas disponibles no avalan la opinión de que los niveles de emigración guarden relación con las tasas regionales de crecimiento demográfico; por ejemplo, en los años cincuenta y sesenta, Europa occidental tuvo un fuerte crecimiento demográfico y era a su vez un importante centro de inmigración.

La pobreza es otro de los factores que se citan como causa fundamental de la migración internacional. Sin embargo, si la pobreza se mide en función de la posición económica relativa del individuo en la sociedad de origen, la mayoría de los emigrantes internacionales no son los más pobres en relación a sus conciudadanos, ya que ellos ocupan la zona intermedia en la escala de ingresos del país de origen.

\footnotetext{
Las características y causas de las migraciones que Ravenstein estableció se resumian en: 1. La mayor parte de los emigrantes se desplaza a lugares cercanos. 2. La emigración a gran distancia se hace a grandes centros. 3. Emigran más los habitantes del campo que los de la ciudad. 4. A distancias cortas emigran más las mujeres y a distancias largas más los hombre. 5 . La in tensidad de los movimientos aumenta con el desarrollo de las actividades comerciales e industriales y con el de los transportes. 6. Las grandes ciudades crecen más por inmigración que por crecimiento vegetativo. 7 . Las migración se dan sobre todo del medio rural a los grandes centros comerciales $e$ industriales. 8. La migración se realiza escalonadamente. 9. La mayoria de los emigrantes son adultos. 10. Las causas principales de los movimientos migratorios son económicas.

Evidentemente, en las migraciones transnacionales muchos de estos puntos no se cumplen. Los emigrantes no se desplazan a lugares cercanos; tampoco, siempre a grandes centros, pues también emigran a las zonas rurales de los países ricos; en determinadas zonas puede ser que haya más emigrantes internacionales de las áreas urbanas; mujeres y hombres emigran de forma muy parecida; el desarrollo de las actividades industriales en los países emisores frena la emigración al exterior. Solo se podría estar de acuerdo en que la emigración, salvo desplazamientos forzados, se realiza escalonadamente; que migran principalmente los adultos, y que genéricamente las causas son económicas; pero ello es una obviedad que no dice nada en sí misma.
} 
En cuanto al concepto de expulsión-atracción, la teoría de Ravenstein y la económica en general se inclina más por el principio de atracción que por el de expulsión. Pero hoy en los movimientos migratorios internacionales se combinan ambos factores. La fuerza de atracción que ejerce el país receptor se regula por medio de cupos legales de inmigrantes; y el crecimiento de los inmigrantes indocumentados no obedece a que las condiciones del foco de atracción sean cada vez mejores, sino a que el efecto de expulsión se acentúa como consecuencia del reiterado fracaso de los proyectos económicos de los países del Tercer Mundo.

Asi pues, la cuestión principal no consta en la elaboración de una teoría que explique con carácter general a todas las migraciones económicas, sino en la respuesta al por qué, en las últimas décadas del siglo $\mathrm{xx}$, en muchas regiones de la Tierra aparece una crisis social tan aguda, capaz de romper las barreras de contención que hasta hace poco parecían existir en los países emisores del Tercer Mundo. Si el diferencial entre pobreza y riqueza es causa de migración, también lo era en los años setenta y ochenta; sin embargo, es a partir de esa década cuando, según nuestros cálculos, el saldo migratorio internacional se multiplica por cuatro entre los años 1985 y 2000.

Por otra parte, aunque la situación de las estructuras económicas y políticas entre naciones explican la predisposición a que se produzcan flujos migratorios, no explican por qué, dentro de un conjunto de individuos con características similares, se termina produciendo la migración de sólo algunos. Esto, en parte, se debe al hecho de la existencia de redes de migrantes entre los países emisores y los receptores que constituyen una estrategia colectiva combinada, destinada a reducir riesgos en la sociedad natal con el envio de remesas ${ }^{2}$. Una vez en marcha la migración internacional, se refuerzan las redes de migración a través de lazos personales basados en el parentesco, la amistad o el origen común que unen a migrantes, ex migrantes y no migrantes, tanto en las zonas de origen como en las de destino. Así la ayuda prestada a los nuevos migrantes por los amigos y familiares ya establecidos en el extranjero reduce los gastos y riesgos de la migración y aumenta la probabilidad de nuevas migraciones. Pero el reforzamiento de las redes solamente explica las ventajas que tiene una parte de la población para la migración de un colectivo

\footnotetext{
2 Las remesas de los emigrantes a las familias proporcionan el capital necesario para aumentar la productividad de los bienes en la comunidad de origen. En 1989, las remesas mundiales ascendieron a 61.000 millones de dólares, cifra muy superior a los 47.000 millones de dólares facilitados ese mismo año por los países de la Organización de Cooperación y Desarrollo Económicos (OCDE) a los paises en desarrollo en concepto de Ayuda Oficial para el Desarrollo (ONU, 1997).
} 
mucho más amplio que quisiera emigrar; las redes por sí mismas no justifican, pues, el fuerte incremento de la migración internacional ni su carácter sostenido.

En el presente estudio, la teoría de las causas de las migraciones internacionales de finales del siglo $x \times$ y principios del $X X \mid$, se basa en los siguientes criterios:

1. La migración internacional es un fenómeno que obedece a la interacción de causas objetivas y subjetivas.

2. Las causas objetivas de las migraciones mundiales se basa en los desequilibrios regionales, a escala mundial.

3. Las causas subjetivas se basan en la evolución social de la percepción del espacio político-económico.

4. La interacción de ambos grupos de causas se produce en determinados sectores sociales de los países emisores, según regiones del mundo.

\subsection{Interacción de las causas objetivas y subjetivas de las migraciones}

En materia social, cuando se habla de causas objetivas, se corre el riesgo de caer en la definición de las mismas como si se tratara de una ciencia física exacta con una ley de causa efecto, y esto no es así. Las causas objetivas deben entenderse como condicionantes que en mayor o menor medida empujan a las personas a emigrar. En el caso de las migraciones forzadas por cuestiones políticas o debido a desastres naturales, la causa tiene tal fuerza que la voluntad de los individuos cuenta poco. En el caso de migraciones económicas el condicionante es menor, pero éste existe, aunque en última instancia será la voluntad de los individuos lo que determinará el acto de migrar.

Así pues, cuando se habla de causas objetivas nos estamos refiriendo a condicionantes que no constituyen causas forzosas para emigrar, pero sí son realidades que obligan a las personas a reflexionar sobre la necesidad o no de emigrar. Desde el punto de vista subjetivo, no todas las personas que desean emigrar lo hacen, pues también existen otros condicionantes disuasorios, que en muchos casos hacen desistir al emigrante potencial de cumplir su deseo; por ejemplo, falta de medios para emprender el viaje, dificultades del viaje, problemas familiares, etc. Además, están los elementos de disuasión por la fuerza, como son los controles fronterizos o la repatriación, una vez que el emigrante ha llegado a su destino. 
Si se entiende por causas objetivas de la emigración las condiciones de vida que impulsan a tomar la decisión de emigrar, hay que suponer que estas condiciones son en el entorno donde se vive peores que en otros lugares a donde se quiere emigrar. Por ejemplo, si en todo el mundo se viviese en las mismas condiciones que en el país emisor de migración, ésta no existiría, pues el emigrante nada tendría que ganar con el cambio. Los condicionantes lo son, pues, cuando existe la diferencia entre países o regiones. Pero, además de existir esta diferencia, debe existir también la percepción de la diferencia. La percepción de la diferencia es subjetiva y, por lo tanto, está sujeta a interpretaciones. Cuando hay una interpretación exagerada de la diferencia, se crea el mito del país de destino, donde el emigrante cree que en él solucionará satisfactoriamente sus problemas.

Pero, en principio, se debe separar el desequilibrio regional objetivo de la percepción del mismo, pues si no existiese el primero, tampoco existiría el segundo. Por ello, nos centraremos primero en el concepto de desequilibrio objetivo entre países y regiones del mundo.

\subsection{Desequilibrios entre países y regiones del mundo}

Teóricamente, el desequilibrio se establece entre dos espacios con condiciones de vida diferentes: entre el ámbito que tiene las condiciones óptimas y el que carece de ellas. En el caso de las migraciones internacionales de finales del siglo $x x$, el factor económico es el principal desequilibrio que impulsa a la migración de los países pobres a los ricos; aunque existen también otros factores, como el mayor nivel en materia de salud, educación, seguridad social, etc., correspondiendo a los países receptores las mejores condiciones.

Pero desde el punto de vista demográfico, los países desarrollados presentan una estructura demográfica muy envejecida, por lo que la renovación de la población en los grupos de edad más jóvenes sólo puede realizarse mediante aportes migratorios. Esta es la ventaja que poseen los países que tienen una estructura demográfica juvenil y dinámica, que en general son los países pobres, generadores de emigración. Lo que ocurre es que esta ventaja de los paises pobres no constituye un factor de atracción, sino de expulsión, al existir un gran número de personas en edad de trabajar, pero sin perspectivas de conseguir empleo. Por el contrario, la desventaja de los países desarrollados en cuanto a estructura demográfica actúa como factor de atracción, ya que se considera necesario para la buena marcha de la economía reducir el desequilibrio demográfico causado por el déficit de los grupos de edad más jóvenes. 
Así pues, en los paises desarrollados existen ventajas que constituyen factores de atracción, pero también carencias que actúan igualmente como factores de atracción; por el contrario, en los países pobres existen carencias que actúan como causas de expulsión y supuestas ventajas en la estructura demográfica que también constituyen factores de expulsión. Los desequilibrios regionales a escala mundial están entrecruzados, y ello, sin duda, favorece las migraciones entre paises en una sola dirección: de los menos desarrollados a los más desarrollados.

\subsection{Percepción subjetiva de los grandes desequilibrios}

Hasta ahora, hemos dado por supuesto que los desequilibrios ente países y regiones se produce porque estos no pueden resolver internamente sus propios desequilibrios. Evidentemente, los países desarrollados necesitarian un cambio de modelo demográfico, si quisieran resolver el envejecimiento de su población, pero no existe en la actualidad ningún indicio de que esto suceda.

De manera rnuy diferente se plantea el problema en los paises pobres. El concepto de países en vías de desarrollo, planteado internacionalmente después de la Segunda Guerra Mundial, no precisa en cuánto tiempo los países pobres debieran culminar el proceso de desarrollo. Sin embargo, las altas tasas de crecimiento vegetativo y de población urbana sí continúan siendo una constante. El desajuste entre crecimiento económico y crecimiento demográfico, entre crecimiento económico y reparto de riqueza y entre el fuerte crecimiento de los asentamientos urbanos y la carencia de infraestructuras, genera objetivamente desequilibrios internos de difícil solución. Y, si con el paso del tiempo estos desequilibrios no mejoran, subjetivamente surge entre la población incertidumbre sobre las posibles soluciones, llegando a producirse también frustración y desesperación.

Esta es la cuestión fundamental: la percepción de la diferencia entre países pobres y ricos se acrecienta, no solamente por el hecho diferencial de las condiciones objetivas entre naciones o regiones del mundo sino también, y sobre todo, por la percepción de la imposibilidad de mejorar las expectativas de vida en un plazo razonable en el país de nacimiento. El desequilibrio entre países no tendría por qué ser motivo de atracción y expulsión de migrantes, si existiera en los respectivos países posibilidades reales, en un periodo de tiempo prudencial, de resolver sus desequilibrios internos. No obstante, hay que tener en cuenta que la decisión de emigrar afecta a una parte de la población que comparte las causas objetivas con la otra parte de la población que decide no emigrar. Este aspecto es más difícil, cuando no imposible, de cuantificar. 


\section{CARACTERIZACIÓN DE LOS DESEQUILIBRIOS SOCIOECONÓMICOS MUNDIALES}

Con el fin de tener una radiografía de los desequilibrios objetivos que inducen a la emigración desde los países pobres al centro desarrollado, se ha cuantificado la situación socioeconómica de 170 países a finales del siglo $\mathrm{xx}$. El procedimiento se ha basado en el análisis factorial. Se ha trabajado con 14 variables que definen las características socioeconómicas más importantes de 170 paises referidas a la segunda mitad de la década de noventa. Estas variables se corresponden con los tres campos que definen los desequilibrios entre sociedades: variables demográficas, socioeconómicas y de calidad de vida (Tabla 1).

Tabla 1. Variables para el análisis de los desequilibrios socioeconómicos del mundo

\begin{tabular}{|c|c|}
\hline Demográficas & Definiciones de las variables \\
\hline Tasa de natalidad (\%o habitantes) & Nacidos por mil habitantes. \\
\hline Tasa de fecundidad (hijos por mujer) & Hijos por mujer en edad fecunda (14 a 49 años). \\
\hline Población urbana $(\%)$ & $\begin{array}{l}\text { Porcentaje de población (Según Naciones Unidas } \\
\text { poblaciones }>10.000 \text { hab.). }\end{array}$ \\
\hline Crecimiento vegetativo (\%) & $\begin{array}{l}\text { Diferencia entre la tasa de natalidad y mortalidad en } \\
\text { porcentaje. }\end{array}$ \\
\hline Población < de 15 años (\%) & $\begin{array}{l}\text { Porcentaje de población menor de } 15 \text { años con re } \\
\text { lación a la población total. }\end{array}$ \\
\hline Población > de 65 años (\%) & $\begin{array}{l}\text { Porcentaje de población mayor de } 65 \text { años con re- } \\
\text { lación a la población total. }\end{array}$ \\
\hline \multicolumn{2}{|l|}{ Socioeconómicas } \\
\hline PNB por habitante $(\$)$ & $\begin{array}{l}\text { Producto Nacional Bruto por habitante en dólares } \\
\text { estadounidenses. }\end{array}$ \\
\hline Población activa: agricultura (\%) & $\begin{array}{l}\text { Porcentaje de población activa en la agricultura res } \\
\text { pecto de la población activa. }\end{array}$ \\
\hline Población activa: industria (\%) & $\begin{array}{l}\text { Porcentaje de población activa en la industria res- } \\
\text { pecto de la población activa. }\end{array}$ \\
\hline Población activa: servicios (\%) & $\begin{array}{l}\text { Porcentaje de población activa en los servicios res- } \\
\text { pecto de la población activa. }\end{array}$ \\
\hline \multicolumn{2}{|l|}{ Calidad de vida } \\
\hline Esperanza de vida al nacer (años) & Esperanza media de vida. \\
\hline Tasa de analfabetismo $(\%)$ & Porcentaje de analfabetos de la población. \\
\hline Número de médicos (\%o habitantes) & Médicos por mil habitantes. \\
\hline Tasa de mortalidad infantil (\%o) & $\begin{array}{l}\text { Niños menores de un año muertos por mil habi } \\
\text { tantes. }\end{array}$ \\
\hline
\end{tabular}

Elaboración propia. 
Las variables demográficas reflejan el crecimiento demográfico, la estructura de la población y la población urbana respecto del total de la población. Las variables socioeconómicas se refieren a la riqueza relativa del país o renta media por habitante y la composición de la población activa. Las variables de calidad de vida definen las condiciones sanitarias, la situación cultural y la esperanza de vida. En estas 14 variables se han resumido, pues, los posibles desequilibrios internos de cada pais en relación con los 170 seleccionados.

La matriz inicial se ha compuesto con los datos de las 14 variables y los 170 países. Recurriendo al análisis factorial se han relacionado las 14 variables de los 170 países, habiendo obtenido una correlación elevada entre las mismas. Entre los factores, uno solo explica el $72,6 \%$ de la varianza (Tablas 2 y 3). Por ello se ha tomado solamente este factor y se ha despreciado el resto de factores por la escasa significación de los mismos. El valor del factor se expresa en cada país en las notaciones factoriales; de esta manera, se han resumido los 14 valores de cada país en uno solo.

Tabla 2. Matriz del primer factor

\begin{tabular}{|c|c|}
\hline \multicolumn{2}{|c|}{ Matriz del primer factor } \\
\hline Variables & Valor factorial \\
\hline Esperanza de vida al nacer (años) & $-0,90124$ \\
\hline Tasa de natalidad (\%o hab.) & 0,94973 \\
\hline Tasa de fecundidad (hijo(s) por m.) & 0,92382 \\
\hline Población urbana $(\%)$ & $-0,78819$ \\
\hline Tasa de analfabetismo (\%) & 0,86016 \\
\hline Crecimiento vegetativo $(\%)$ & 0,84594 \\
\hline Tasa de mortalidad infantil $(\% \circ)$ & 0,89099 \\
\hline Número de médicos $(\% \circ$ hab.) & $-0,79158$ \\
\hline PNB por habitante $(\$)$ & $-0,65299$ \\
\hline Población activa: agricultura (\%) & 0,89463 \\
\hline Población activa: industria (\%) & 0,81589 \\
\hline Población activa: servicios (\%) & 0,77068 \\
\hline Población < de 15 años $(\%)$ & 0,95019 \\
\hline Población > de 65 años (\%) & $-0,84300$ \\
\hline
\end{tabular}

Elaboración propia. 
Tabla 3. Varianza de los factores

\begin{tabular}{|c|c|c|}
\hline \multicolumn{3}{|c|}{ Varianza explicada de los factores } \\
\hline Factores & $(\%)$ & (\%) Acumulado \\
\hline 1. Factor & 72,6 & 72,6 \\
\hline 2. Factor & 8,5 & 81,1 \\
\hline 3. Factor & 5,4 & 86,5 \\
\hline 4. Factor & 3,8 & 90,3 \\
\hline 5. Factor & 2,5 & 92,8 \\
\hline 6. Factor & 2,3 & 95,0 \\
\hline 7. Factor & 1,4 & 96,4 \\
\hline 8. Factor & 1,2 & 97,6 \\
\hline 9. Factor & 0,9 & 98,5 \\
\hline $10 .^{\circ}$ Factor & 0,6 & 99,1 \\
\hline 11. ${ }^{\circ}$ Factor & 0,4 & 99,5 \\
\hline 12. ${ }^{\circ}$ Factor & 0,3 & 99,8 \\
\hline $13 .^{\circ}$ Factor & 0,2 & 99,9 \\
\hline 14. ${ }^{\circ}$ Factor & 0,1 & 100,0 \\
\hline
\end{tabular}

Elaboración propia.

El primer factor, que explica el 72,6 de la varianza, representa dos modelos de sociedades, expresados, por un lado, en las variables con correlaciones positivas y, por otro, en las variables con correlaciones negativas. El modelo expresado en las siete variables de correlación positiva presenta sociedades con fuerte dinamismo demográfico, un precario desarrollo económico y escasa calidad de vida. Ello está representado en las tasas de natalidad y de fecundidad más altas, el crecimiento vegetativo más elevado, el mayor grupo de edad de población menor de 15 años, las mayores tasas de empleo agrícola, la mayor tasa de analfabetismo y la tasa de mortalidad infantil más alta.

En oposición, está el otro modelo de sociedades, expresado en la correlación de las variables negativas; se caracteriza por su poco dinamismo demográfico, excelente desarrollo económico y buena calidad de vida. Ello se expresa en el mayor porcentaje de viejos, en el más elevado PNB por habitante $(\$)$, la población activa industrial y de servicios más numerosa, el mayor porcentaje de población urbana, la mayor esperanza de vida al nacer y el mayor número de médicos por mil habitantes.

Desde el punto de vista de los desequilibrios, en las sociedades con correlaciones positivas el desequilibrio interno se manifiesta, principalmente, en el bajo PNB por habitante (\$), la menor población activa industrial y de servicios, la menor esperanza de vida al nacer y el menor número de médicos por mil habitantes. En las sociedades con correlaciones negativas el desequilibrio interno se expresa principalmente por las bajas 
tasas de fecundidad y natalidad, el bajo crecimiento vegetativo y el menor porcentaje de menores de 15 años.

Pero estos desequilibrios internos y entre naciones tienen un valor particular en cada pais, que se expresa cuantitativamente en las notaciones factoriales del denominado factor socioeconómico. Según el resultado de las notaciones factoriales, se han agrupado los países conformando cuatro tipologías, dos para las notaciones negativas y dos para las positivas (Tabla 4 y Mapa 1).

Tabla 4. Matriz de notaciones factoriales (14 variables por 170 países)

\begin{tabular}{|c|c|c|c|c|c|c|c|}
\hline MODELO & & MODELO & & MODELO & & MODELO & \\
\hline $\begin{array}{c}\text { Países con } \\
\text { desarrollo o } \\
\text { moderado } \\
\text { desarrollo } \\
\text { socioeconómico } \\
\text { y situación } \\
\text { demográfica } \\
\text { estancada }\end{array}$ & $\begin{array}{l}\text { Nota- } \\
\text { cio- } \\
\text { nes }\end{array}$ & $\begin{array}{l}\text { Países con } \\
\text { moderado } \\
\text { desarrollo } \\
\text { socioeconómico } \\
\text { y sítuación } \\
\text { demográfica } \\
\text { de moderada } \\
\text { a dinámica }\end{array}$ & $\begin{array}{l}\text { Nota- } \\
\text { cio- } \\
\text { nes }\end{array}$ & $\begin{array}{l}\text { Paises con } \\
\text { moderado } \\
\text { desarrollo o } \\
\text { subdesarrollo } \\
\text { socioeconómico } \\
\text { y situación } \\
\text { demográfica } \\
\text { dinámica }\end{array}$ & $\begin{array}{c}\text { Nota- } \\
\text { cio- } \\
\text { nes }\end{array}$ & $\begin{array}{l}\text { Países con } \\
\text { subdesarrollo } \\
\text { socioeconómico } \\
\text { y situación } \\
\text { demográfica } \\
\text { muy dinámica }\end{array}$ & $\begin{array}{l}\text { Nota- } \\
\text { cio- } \\
\text { nes }\end{array}$ \\
\hline ania & $-1,69$ & Taiv & $-0,99$ & $\begin{array}{l}\text { Dominicana } \\
\text { República }\end{array}$ & 0,01 & Laos & 1,01 \\
\hline Italia & $-1,67$ & Israel & $-0,96$ & Guyana & 0,02 & Kenya & 1,03 \\
\hline Bélgica & $-1,66$ & Chipre & $-0,95$ & Sri & 0,02 & Guine & 1,04 \\
\hline Japón & $-1,63$ & Cuba & $-0,94$ & Perú & 0,03 & Congo Rep. Dem. & $.1,05$ \\
\hline Suiza & $-1,63$ & Rumania & $-0,93$ & Turquia & 0,04 & Madagascar & 1,15 \\
\hline Luxemburgo & $-1,58$ & Yugoslavia & $-0,92$ & Uzbekistán & 0,04 & Camboya & 1,15 \\
\hline Dinamarca & $-1,56$ & Argentina & $-0,90$ & Albania & 0,09 & Costa Marfil & 1,16 \\
\hline Suecia & $-1,54$ & Polonia & $-0,89$ & ndia & 0,10 & Zambia & 1,17 \\
\hline España & $-1,52$ & Corea del Sur & $-0,82$ & Jordania & 0,10 & Senegal & 1,18 \\
\hline Austria & $-1,51$ & Armenia & $-0,79$ & Turkme & 0,10 & ria & 1,19 \\
\hline lega & $-1,50$ & Molc & $-0,74$ & Ará & 0,13 & To & 1,22 \\
\hline Francia & $-1,49$ & Bosnia/Herz. & $-0,72$ & Argelia & 0,16 & Maurita & 1,24 \\
\hline Gran Bretaña & $-1,43$ & $\begin{array}{l}\text { Emiratos } \\
\text { Árabes Unidos }\end{array}$ & $-0,72$ & Filipinas & 0,16 & Nepal & 1,24 \\
\hline País & $-1,42$ & Kuwait & $-0,70$ & & 0,19 & & 1,24 \\
\hline Fink & $-1,35$ & $\begin{array}{l}\text { Trinidad y } \\
\text { Tobago }\end{array}$ & $-0,69$ & Marruecos & 0,24 & Burundi & 1,27 \\
\hline Repúb. & $-1,3$ & Chile & -0 & & & & 1,2 \\
\hline & $-1,31$ & Qatar & $-0,64$ & Salvador El & 0,28 & & 1,30 \\
\hline Bulgaria & $-1,30$ & Kazajs & $-0,62$ & Paraguay & 0,28 & Gambia & 1,30 \\
\hline Estados Unidos & $-1,30$ & Brunei & $-0,59$ & Belice & 0,33 & Guinea Bissau & 1,32 \\
\hline Islandia & $-1,30$ & Seychelles & $-0,57$ & Egipto & 0,38 & Mozambique & 1,34 \\
\hline Canadá & $-1,28$ & Libano & $-0,53$ & Maldivas & 0,39 & Benin & 1,34 \\
\hline Grecia & $-1,27$ & Mauricio & $-0,49$ & Lesotho & 0,42 & Afganistán & 1,35 \\
\hline Australia & $-1,26$ & Macedonia & $-0,47$ & Nicaragua & 0,42 & $\begin{array}{l}\text { Centroafricana } \\
\text { República }\end{array}$ & 1,36 \\
\hline
\end{tabular}


Tabla 4. Matriz de notaciones factoriales (14 variables por 170 paises) (continuación)

\begin{tabular}{|c|c|c|c|c|c|c|c|}
\hline \multicolumn{2}{|c|}{ MODELO 1} & \multicolumn{2}{|c|}{ MODELO 2} & \multicolumn{2}{|c|}{ MODELO 3} & \multicolumn{2}{|c|}{ MODELO 4} \\
\hline $\begin{array}{c}\text { Paises con } \\
\text { desarrollo o } \\
\text { moderado } \\
\text { desarrollo } \\
\text { socioeconómico } \\
\text { y situación } \\
\text { demográfica } \\
\text { estancada }\end{array}$ & $\begin{array}{c}\text { Nota- } \\
\text { cio- } \\
\text { nes }\end{array}$ & $\begin{array}{c}\text { Paises con } \\
\text { moderado } \\
\text { desarrollo } \\
\text { socioeconómico } \\
\text { y situación } \\
\text { demográfica } \\
\text { de moderada } \\
\text { a dinámica }\end{array}$ & $\begin{array}{l}\text { Nota- } \\
\text { cio- } \\
\text { nes }\end{array}$ & $\begin{array}{c}\text { Países con } \\
\text { moderado } \\
\text { desarrollo o } \\
\text { subdesarrollo } \\
\text { socioeconómico } \\
\text { y situación } \\
\text { demográfica } \\
\text { dinámica }\end{array}$ & $\begin{array}{l}\text { Nota- } \\
\text { cio- } \\
\text { nes }\end{array}$ & $\begin{array}{c}\text { Países con } \\
\text { subdesarrollo } \\
\text { socioeconómico } \\
\text { y situación } \\
\text { demográfica } \\
\text { muy dinámica }\end{array}$ & $\begin{array}{l}\text { Nota- } \\
\text { cio- } \\
\text { nes }\end{array}$ \\
\hline Malta & $-1,22$ & Bahrein & $-0,46$ & Libia & 0,42 & Yemen & 1,38 \\
\hline Eslovenia & $-1,22$ & Venezuela & $-0,42$ & Vietnam & 0,46 & Somalia & 1,44 \\
\hline Letonia & $-1,21$ & Azerbaiján & $-0,41$ & Siria & 0,48 & Tanzania & 1,46 \\
\hline Ucrania & $-1,20$ & Corea Norte & $-0,37$ & Samoa Occ. & 0,48 & Uganda & 1,47 \\
\hline Portugal & $-1,20$ & Dominica & $-0,35$ & Iraq & 0,50 & Eritrea & 1,50 \\
\hline Rusia & $-1,18$ & Panamá & $-0,33$ & Bolivia & 0,52 & Sierra Leona & 1,51 \\
\hline Estonia & $-1,16$ & Jamaica & $-0,29$ & Irán & 0,53 & Malí & 1,51 \\
\hline Nueva Zelanda & $-1,16$ & Costa Rica & $-0,29$ & Djibuti & 0,58 & Rep. Guinea & 1,52 \\
\hline Bielorrusia & $-1,16$ & Surinam & $-0,29$ & Gabón & 0,59 & Bhután & 1,53 \\
\hline Singapur & $-1,15$ & Colombia & $-0,23$ & Honduras & 0,62 & Ruanda & 1,53 \\
\hline Eslovaquia & $-1,12$ & Brasil & $-0,22$ & India & 0,64 & Burkina Faso & 1,58 \\
\hline Uruguay & $-1,11$ & México & $-0,21$ & Myanmar & 0,65 & Etiopia & 1,60 \\
\hline Croacia & $-1,09$ & Kirguisistán & $-0,20$ & Namibia & 0,69 & Malawi & 1,64 \\
\hline Lituania & $-1,05$ & China & $-0,07$ & Cabo Verde & 0,69 & Niger & 1,71 \\
\hline Irlanda & $-1,02$ & Mongolia & $-0,03$ & Swazilandia & 0,72 & & \\
\hline \multirow[t]{15}{*}{ Georgia } & $-1,02$ & Ecuador & $-0,02$ & Guatemala & 0,73 & & \\
\hline & & Malasia & $-0,02$ & Botswana & 0,74 & & \\
\hline & & Sudáfrica & $-0,02$ & Congo & & & \\
\hline & & República de & & República del & 0,75 & & \\
\hline & & Túnez & $-0,02$ & $\begin{array}{l}\text { Zimbabwe } \\
\text { Papua Nueva }\end{array}$ & 0,81 & & \\
\hline & & & & $\begin{array}{l}\text { Guinea } \\
\text { Santo Tomé }\end{array}$ & 0,84 & & \\
\hline & & & & y Príncipe & 0,89 & & \\
\hline & & & & Pakistán & 0,89 & & \\
\hline & & & & Vanuatu & 0,90 & & \\
\hline & & & & Bangladesh & 0,94 & & \\
\hline & & & & Ghana & 0,95 & & \\
\hline & & & & Omán & 0,96 & & \\
\hline & & & & Camerún & 0,98 & & \\
\hline & & & & Nigeria & 0,99 & & \\
\hline & & & & Haití & 1,00 & & \\
\hline
\end{tabular}

Elaboración propia. 
Evidentemente, en las zonas intermedias de las clasificaciones se encuentra una serie de paises con notaciones que son difíciles de tipificar, pero convencionalmente se les ha asignado al grupo más afín ${ }^{3}$. Geográficamente se representa en el mapa núm. 1.

El modelo 1 (notaciones $-1,69$ a -1 ), que comprende 39 países con alto o moderado desarrollo socioeconómico y situación demográfica estancada, se localiza en Europa, Rusia, América del Norte, AustraliaNueva Zelanda y Japón; solamente Uruguay en América del Sur, se sitúa en ese grupo ${ }^{4}$.

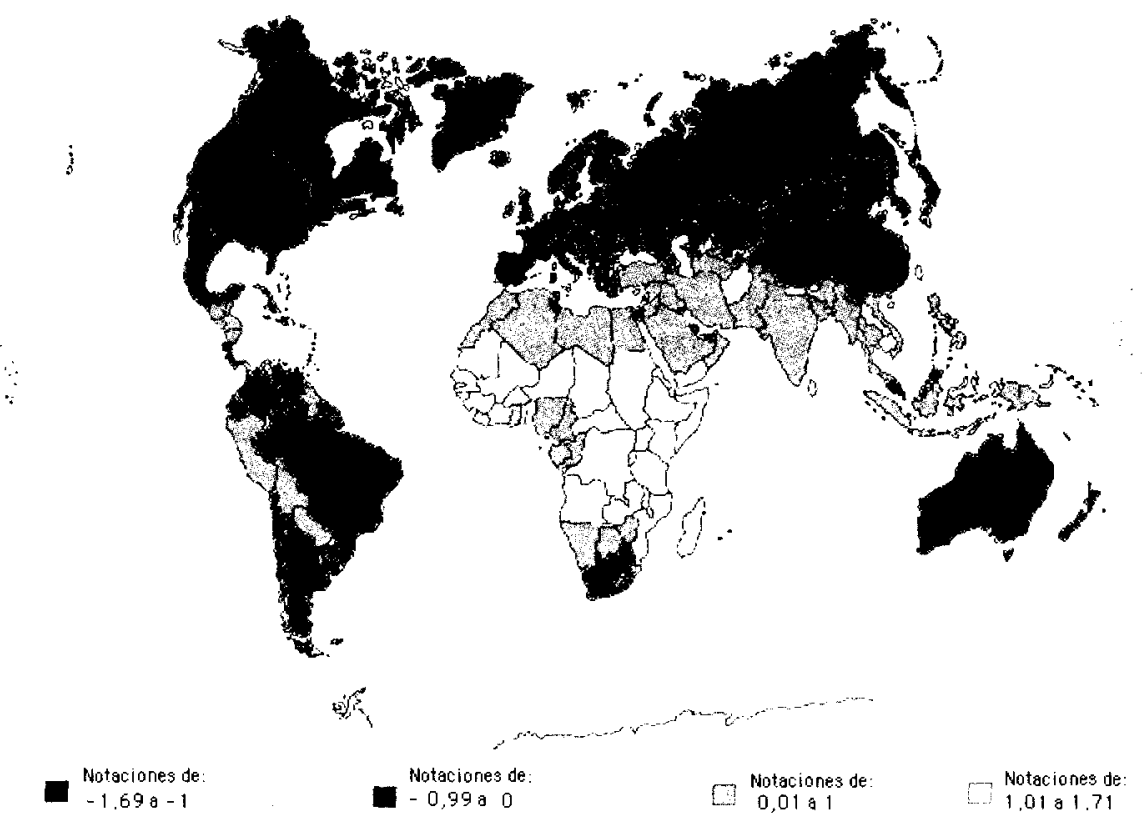

Mapa 1. Representación de las notaciones factoriales según tipología socioeconómica.

Elaboración propia.

${ }_{3}$ Se puede considerar que los desequilibrios reflejados en la matriz de notaciones factoriales, aunque están basados en datos registrados entre 1994 y 1996, son desequilibrios estructurales que ilustran relativamente bien el estado de los paises de un periodo histórico que se puede estimar como de finales del siglo $x x$.

4 Hay que tener en cuenta que, en el análisis matemático, el modelo ideal demográfico es el 4 y el modelo ideal de desarrollo es el 1 ; las notaciones reflejan por correlación inversa esas diferencias. 
El modelo 2 (notaciones $-0,99$ a 0 ) incluye 42 países con moderado desarrollo socioeconómico y situación demográfica de moderada a dinámica, que se localizan en América Latina, Asia Oriental y, en África, Sudáfrica y Túnez. El modelo 3 (notaciones 0,01 a 1 ) es el grupo más numeroso con 52 países de moderado desarrollo o subdesarrollo socioeconómico y situación demográfica dinámica; se localizan en América central, en la región del norte de los Andes; en el norte, oeste y sur de África; en Asia occidental y meridional, y en parte de Oceanía.

El modelo 4 (notaciones 1,01 a 1,71) comprende 37 países con subdesarrollo socioeconómico y situación demográfica muy dinámica; se localizan en Asia (Laos, Afganistán, Yemen, Nepal y Bhután); el resto de países se sitúan en el centro, este y oeste de África.

Se puede apreciar cómo la situación a la que se ha llegado en el mundo a finales del siglo xx, se correlaciona inversamente desde el centro más desarrollado a los países más pobres. En el mapa núm. 1, se puede observar que el mundo, con la excepción de Australia, se divide entre el Norte, económicamente desarrollado, con demografía estancada y esperanza de vida alta, y el Sur, con subdesarrollo económico, demografía dinámica y esperanza de vida media o baja.

\section{EVALUACIÓN DE LAS MIGRACIONES INTERNACIONALES}

Es evidente que la migración internacional desde los países pobres hacia las regiones desarrolladas se está convirtiendo en un factor importante de cambio socioeconómico en el mundo. Por ello es de tanto interés conocer su magnitud. La evaluación de los movimientos migratorios internacionales se puede realizar básicamente con dos metodologías diferentes; la primera, método directo, se basa en elaborar las estadísticas de migraciones a partir de los datos registrados de emigrantes o inmigrantes; la segunda, método indirecto, consiste en el cálculo de las transferencias de población, denominados saldos netos de migración, obtenidas de forma indirecta a partir de los datos de crecimiento natural y del crecimiento real de la población.

En lo que se refiere al método basado en el registro de migrantes, pese a la creciente importancia de la migración internacional, con frecuencia se carece de estadísticas adecuadas para caracterizar las corrientes migratorias y observar cómo van cambiando con el tiempo. Es posible obtener datos sobre la migración internacional en tres tipos 
de fuentes: administrativas, estadísticas de fronteras y estudios de hogares ${ }^{5}$.

En el presente estudio, con el fin de tener una visión general de los saldos migratorios entre regiones del mundo, se ha utilizado el método indirecto, calculándose los saldos migratorios netos y las tasas netas de transferencia de población. El hecho de utilizar este método es porque es el único que permite hacer una estimación de los saldos netos entre las grandes regiones del mundo, ya que las fuentes que registran directamente las migraciones no aportan este dato por regiones del mundo. Por ejemplo, África es un continente que tiene un saldo de población negativo; sin embargo, en el registro directo de migrantes efectuado por la ONU, este dato no queda explícito, ya que en los 15,6 millones de migrantes registrados en 1990 se incluyen todos los nacidos en otro país, sea africano o de otro continente pero no se ofrecen los saldos netos de transferencia de población del continente africano a otras regiones del mundo ${ }^{6}$.

Para tener una referencia aceptable de los saldos migratorios en el tiempo, se ha calculado en periodos de varios años que convencionalmente suelen ser de cinco. En el presente estudio se ha tomado, por una parte, el periodo

\footnotetext{
${ }^{5}$ Entre las fuentes administrativas, cabe mencionar los registros de extranjeros y la información obterida como consecuencia de visados, permisos de residencia, permisos de trabajo y permisos de salida. Las estadísticas fronterizas comprenden todos los datos reunidos durante el control de fronteras y pueden ser de carácter administrativo o puramente estadisticos; sin embargo, estas estadísticas solo proporcionan datos fiables sobre la migración internacional en unos pocos paises. Los estudios de hogares comprenden censos y diversos tipos de encuestas a hogares. Estos censos se suelen usar para medir la población de migrantes. A tal efecto, la condición de migrante internacional se define, en general, en función del lugar de nacimiento, es decir, sería la persona naciaa en un país extranjero del que trabaja o busca trabajo. Sin embargo, no toda persona que cruza una frontera internacional es un migrante internacional. Es necesario establecer criterios para distinguir entre migrantes internacionales y viajeros internacionales en general. La duración de la estancia en el pais de destino puede usarse para establecer tal distincion, pero, debido a que algunos turistas pueden permanecer más tiempo que un emigrante temporal, la duración de la estancia no puede ser un criterio suficiente. Desde el punto de vista del Estado, la caracterización del migrante internacional depende de la ciudadanía y del motivo de la admisión, ambos, criterios jurídicos. Migración internacional y desarrollo. ONU, 1997.

${ }^{6}$ Los datos natalidad y mortalidad y de crecimiento total de la población se obtienen a través de los registros que a tal efecto realizan los diferentes paises. Las transferencias netas de migración, o saldo migratorio neto, se pueden estimar a partir del crecimiento total de la población y del crecimiento vegetativo (natalidad-mortalidad), hallando la diferencia entre ambos crecimientos. Obviamente, cuando se toma como ámbito de análisis el mundo, el crecimiento vegetativo y el crecimiento total de la población mundial son iguales; las diferencias entre ambos crecimientos solamente se produce a nivel regional. Las cifras absolutas de transferencia neta de migración de la población, asi como las de natálidad y mortalidad, puestas en relación con la población total del ámbito de referencia, ofrecen valores relativos que se expresan en tasas por mil habitantes y año. En la actualidad, se puede decir que en todos los paises del mundo, la tasa de transferencia migratoria interviene en el crecimiento o decrecimiento de la población.
} 
1980-1985; por otra, se ha tenido en cuenta el periodo 1995-2000. El hecho de tomar dos periodos de cinco años, distantes entre sí en 15 años, es debido a que se parte de la hipótesis de que ha sido entre 1980-1985 y 1995-2000 cuando se han conformado las condiciones y factores de los movimientos migratorios actuales. Con ello, se ha podido realizar una estimación hasta el año 2025, aplicando la variación de los saldos migratorios del periodo 1980-1985 a 19952000 hasta el 2025. Las regiones del mundo son las establecidas en la tabla número 2 del Informe Mundial sobre Asentamientos Humanos (ONU, 1987).

Tabla 5. Macroregiones y regiones del mundo ${ }^{7}$

\begin{tabular}{lc}
\hline África & Europa \\
África oriental & Europa oriental \\
África central & Europa septentrional \\
África septentrional & Europa meridional \\
África meridional & Europa occidental \\
África occidental & América Latina y el Caribe \\
Asia & Caribe \\
China & Centroamérica \\
Japón & América del Sur tropical \\
Resto Asia oriental & América del Sur templada \\
Asia centromeridional & América del Norte \\
Asia sudoriental & Oceanía \\
Asia occidental & Australia-Nueva Zelanda \\
& Melanesia, Micronesia y Polinesia \\
& URSS (1980-1985) Antigua URSS (1995-2000) \\
\hline
\end{tabular}

Fuente: Tabla 2 del Informe Mundial sobre Asentamientos Humanos. ONU, 1987.

Los saldos migratorios netos varían según el ámbito de estimación. Los ámbitos en el presente estudio son nacional, regional y supraregional ${ }^{8}$. Obviamente, el ámbito nacional registra unos saldos netos superiores a los

7 El hecho de mantener la URSS como región en periodos posteriores a su desaparición es debido a la necesidad de mantener la referencia del periodo 1980-1985 tanto para su comparación como para las proyecciones. América del Norte y la ex URSS se contabilizan, a la vez, como regiones y como macroregiones.

${ }^{8}$ Los únicos datos que se ha encontrado comparables, entre los datos obtenidos a partir del registro de inmigrantes y los obtenidos a partír de los saldos netos de migración, son los relativos a la Macroregión de América del Norte, siendo estos los siguientes: para el periodo 1980-1985, los datos de registro de inmigrantes era de 3,395 millones, y los saldos netos ofrecian 2,561 millones. Para el periodo 1985-1990, los datos de registro de inmigrantes era de 3,718 millones, y los saldos netos ofrecían 3,704 millones. Para el periodo 1990-1995 los datos de registro de inmigrantes era de 5,019 millones, y los saldos netos ofrecian 4,847 millones. Si bien, se aprecian diferencias no se pueden considerar sustanciales. La metodología de los saldos netos basada en el crecimiento de la población resulta ligeramente inferior; no obstante, de la fuente de registro de migrantes falta de deducir la parte de emigración de América del Norte a otras regiones para obtener el saldo neto por esa metodologia. 
de la región y ésta los registra superiores a los de la macroregión. Es decir, los migrantes que cambian de país no siempre cambian de región, y los que cambian de región no siempre cambian de macroregión ${ }^{9}$. Una cuestión a tener en cuenta, cuando se estiman los saldos migratorios netos para todas las regiones del mundo, es que la suma de todos los saldos, es decir, el saldo migratorio mundial neto, deberá ser igual a cero, pues el saldo positivo y negativo debe ser el mismo; por lo tanto, se ha procedido a los ajustes necesarios para conseguir ese saldo igual a cero, pero en ningún caso ha supuesto apartarse significativamente de los datos iniciales.

\section{ANÁLISIS DE LOS SALDOS MIGRATORIOS NETOS POR GRANDES REGIONES}

Los cálculos realizados sobre transferencias de población entre regiones y macroregiones del mundo, para los periodos 1980-1985 y 1995-2000 se resumen en los cuadros 6 y 7 . Ambos cuadros presentan información relativa al número de habitantes por regiones del mundo, crecimiento real y crecimiento vegetativo de la población, saldos netos de migración, así como las tasas correspondientes de crecimiento real, crecimiento vegetativo y transferencia de población. Con el fin de centrar los comentarios, éstos se van a referir a los saldos migratorios netos y a las tasas de transferencia de población en los dos periodos, mostrando también las diferencias entre ambos.

\subsection{Periodo $1980-1985$}

El periodo de 1980-1985 es un periodo en el que la situación internacional se encuentra políticamente dominada por la política de bloques; la descolonización de los paises del Tercer Mundo prácticamente ha tocado a su fin; económicamente las expectativas de desarrollo se mantienen puestas principalmente en el ámbito nacional. Con ello, aunque las diferencias entre el Norte y el Sur son grandes, no se han desarrollado las condiciones subjetivas para la emigración internacional. No obstante, la migración de centros emisores de regiones pobres y receptores de regiones ricas comienza a tener importancia.

\footnotetext{
9 Los datos de número de habitantes de los paises del mundo de los años 1980, 1985, 1995 , 2000, y las estimaciones para el 2025, están sacados de las tablas de población publicadas por la FAO. Los paises que se han tenido en cuenta son todos los del mundo en el periodo 1980-1985, y 150 en el periodo 1995-2000, así como en la estimación para el 2025, que contemplan el $99,6 \%$ de la población del mundo en los tres periodos analizados.
} 


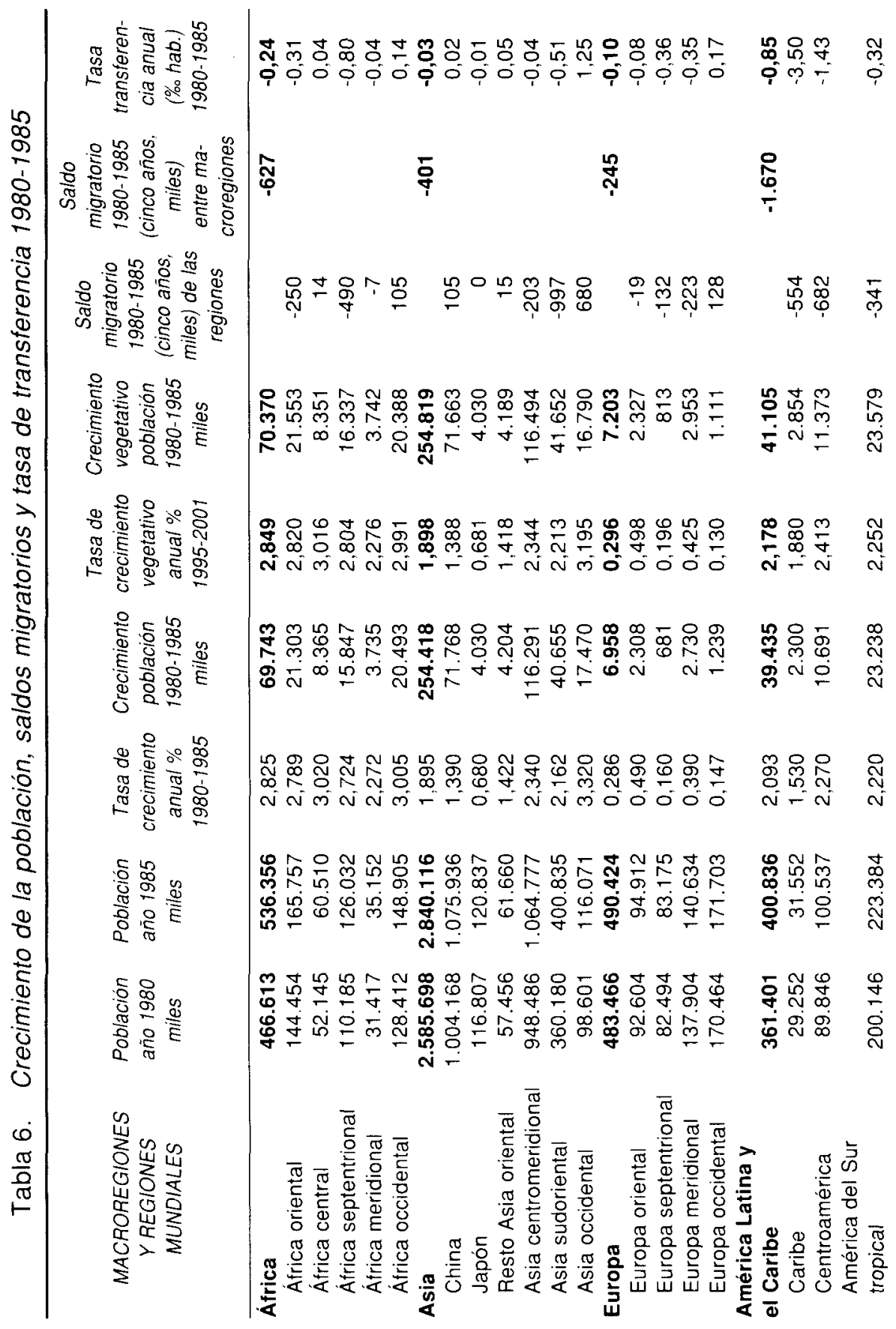




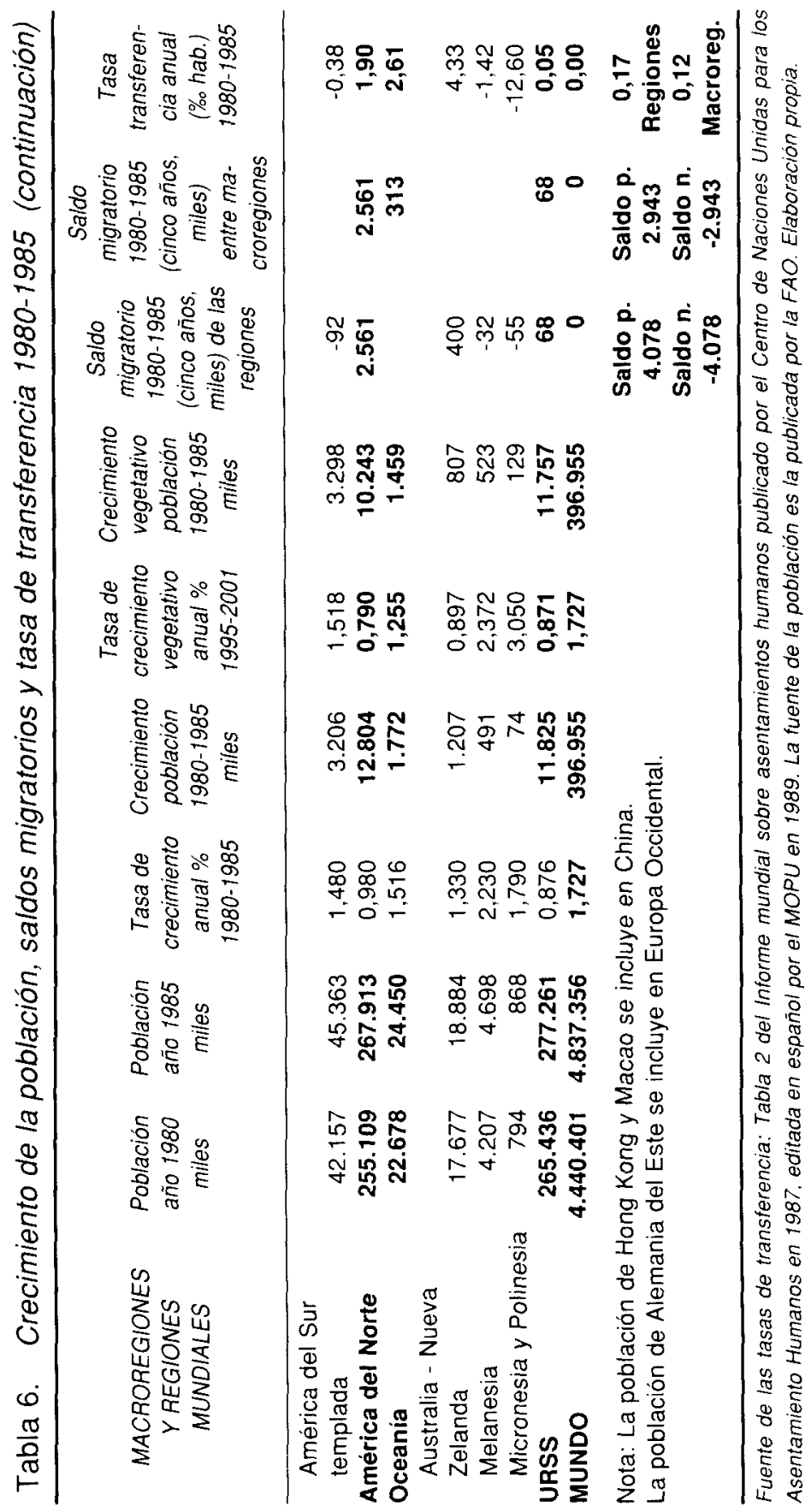


En el conjunto mundial, el saldo migratorio estimado de las regiones fue, entre 1980-1985, de 4 millones; de ellos 2,9 millones tuvo lugar entre macroregiones. Las macroregiones emisoras estaban formadas por África con un saldo emigratorio en los cinco años de referencia de 627.000 emigrantes, Asia con 401.000, Europa con 245.000 y América Latina con 1,7 millones. Las macroregiones receptoras eran América del Norte con un saldo inmigratorio de 2,5 millones, Oceanía con 313.000 inmigrantes y la URSS con otros 68.000 .

Por regiones, en África tuvieron saldo positivo la región central y la occidental. Asia tenía en la región occidental el destino más importante de la migración del continente con 680.000 inmigrantes en los cinco años de referencia, ello debido a la atracción de los países petrolíferos; la región asiática emisora más fuerte fue la sudoriental. En Europa, solamente la región occidental tuvo un saldo positivo con 128.000 inmigrantes; el resto emitió población fuera de su región, particularmente Europa meridional con un saldo de 223.000 emigrantes. En América Latina todas las regiones fueron emisoras de población, siendo la más importante Centroamérica, con un saldo de 682.000 emigrantes, seguida del Caribe, con 554.000. América del Norte fue el principal receptor de inmigración mundial con un saldo positivo de 2,5 millones de inmigrantes. Oceanía, Australia y Nueva Zelanda registran saldo positivo, con aportes principalmente de fuera de la macroregión. Melanesia, Micronesia y Polinesia presentan saldos negativos.

Las tasas de transferencia anual positivas más importantes las tienen Australia y Nueva Zelanda, habiendo recibido 4,33 inmigrantes por cada 1.000 habitantes de la región (\%o/hab.); le sigue América del Norte con $1,90 \% / h a b$. En las tasas de transferencia negativas destaca América Latina con $-0,85 \%$ /hab., seguida de lejos por África con $-0,24 \% / \mathrm{hab}$.

En cifras absolutas supone que, de los 4,1 millones de migrantes en el mundo, 3 millones cambiaron de macroregión, mientras que 1,1 millones se trasladaron dentro de su macroregión; de ello se deduce que la migración entre macroregiones fue mucho más importante que la interna de las respectivas macroregiones: la primera representa el $72,2 \%$ de los migrantes y la segunda el $27,8 \%$.

\subsection{Periodo $1995-2000$}

La situación política y económica en 1995-2000 era muy diferente a la de 1980-1985; el agravamiento de la deuda en la mayoría de los países del Tercer Mundo ha ido dificultando las expectativas de desarrollo en estos países. El final de la Guerra Fría suponía para muchos países el final del pa- 
raguas político y económico de las superpotencias. En la segunda mitad del decenio de 1980 y comienzos de 1990, los desequilibrios demográficos y del mercado laboral, asi como las diferencias cada vez mayores en el crecimiento económico entre los diversos países y regiones, debido a los efectos de la globalización, contribuyeron a intensificar las presiones migratorias.

En los años noventa, la desintegración de la Unión Soviética y su reconfiguración en los Estados sucesores, los trascendentales cambios políticos, económicos y sociales de Europa Centro-Oriental, la disolución de la ex Yugoslavia y el prolongado conflicto entre grupos étnicos rivales, la crisis del Golfo Pérsico de 1990 y la lucha civil en Ruanda, fueron algunos de los acontecimientos que desencadenaron los enormes e imprevistos aumentos de los movimientos migratorios internacionales que acapararon la atención de los foros internacionales.

Pero, al mismo tiempo que se estaban desarrollando estos acontecimientos, se venían configurando las condiciones que darían lugar a un incremento generalizado y sostenido de los movimientos migratorios, debido al fracaso de las políticas de desarrollo en la mayoría de los países del Tercer Mundo; en la década de los noventa tuvo lugar la crisis económica rusa, la crisis asiática y la de algunos países latinoamericanos como Argentina. En África, la República Sudafricana es de los pocos países que logró combinar la tendencia hacia una estabilidad política y el desarrollo económico.

En el conjunto mundial, el saldo migratorio de las grandes regiones ha pasado de los 4,1 millones en el quinquenio 1980-1985 a 18,3 millones en el quinquenio 1995-2000; de este saldo, 13,7 millones son migrantes entre macroregiones, cifra muy superior a los 3 millones del periodo 1980-1985. Las macroregiones emisoras han experimentado cambios importantes: Europa deja de ser emisora; en África los emigrantes pasaron de 627.000 en 1980-1985 a 4,3 millones en 1995-2000, los de Asia de 401.000 a 6,8 millones, y en América Latina, de 1,7 millones se ha pasado a 2,6 millones.

Las macroregiones receptoras han incrementado notablemente su saldo migratorio positivo: América del Norte de 2,6 millones en 1980-1985 a 6 millones en 1995-2000, Oceanía de 313.000 a 523.000, y la ex URSS de 68.000 a 2,3 millones. El cambio más significativo tuvo lugar en Europa que se convirtió en macroregión mundial receptora, con un saldo de 4,9 millones de inmigrantes. Respecto a las macroregiones emisoras, África tuvo un saldo migratorio negativo de 4,3 millones de personas; las regiones central y occidental, que en el periodo 1980-1985 tuvieron saldo positivo, han pasado a tenerlo negativo; sólo la región de África meridional ha registrado un saldo positivo de 217.000 inmigrantes (ello fue debido a la transformación política de Sudáfrica). 


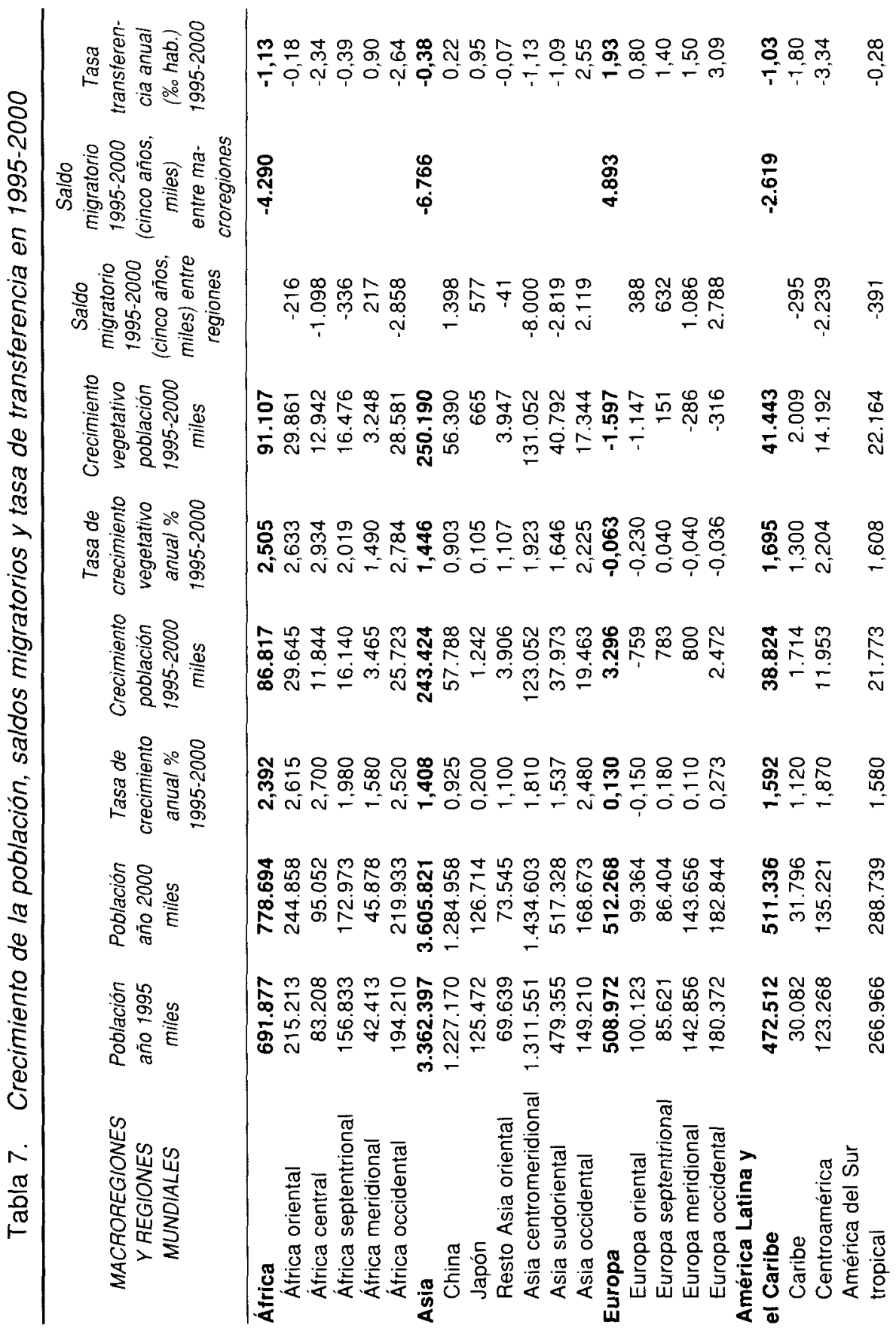




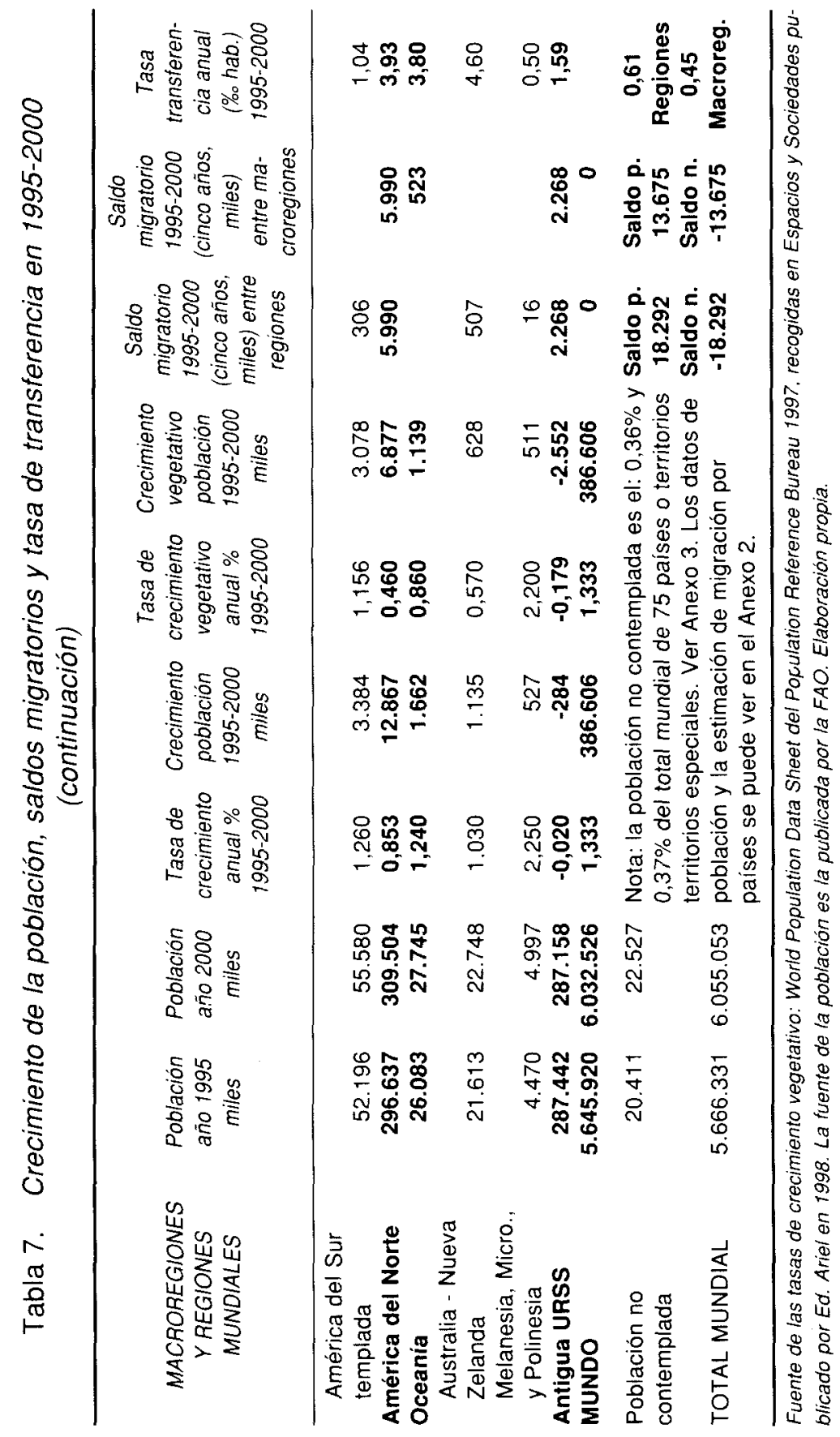


En Asia, la región occidental, que en el periodo 1980-1985 era el destino más importante de la migración del continente con un saldo de 680.000 inmigrantes, vio incrementado este número hasta 2,1 millones en 1995-2000; Japón, con un saldo de 577.000 inmigrantes, y China, con 1,4 millones, aparecen como centros receptores importantes. La región asiática con mayor número de emigrantes es la centromeridional, con un saldo de 8 millones, desplazando al segundo puesto a la sudoriental que fue primera en el periodo 1980-1985.

En Europa, que en el periodo 1980-1985 solo la región occidental registró saldo positivo, en 1995-2000 todas sus regiones son centros receptores de inmigración: en Europa Occidental el número de inmigrantes ha pasado de 128.000 en 1980-1985 a 2,8 millones en 1995-2000; pero el cambio más significativo lo ha experimentado Europa meridional que, de tener un saldo negativo, ha pasado a un saldo positivo de 1,1 millones. En América Latina, en 1980-1985 todas las regiones fueron emisoras de población; sin embargo, en el periodo 1995-2000 la región de América templada tuvo un ligero saldo positivo de 306.000 inmigrantes; no obstante, en Centroamérica los emigrantes pasaron de 682.000 a 2,2 millones; en la región del Caribe el saldo descendió de 554.000 a 295.000 emigrantes. América del Norte sigue siendo el principal centro receptor de migración del mundo, pasando de un saldo de 2,6 millones de inmigrantes a 6 millones. En Oceanía, Australia y Nueva Zelanda mantienen el volumen de inmigración, con un saldo de 507.000 en 1995-2000. La región de Melanesia, Micronesia y Polinesia pasa de tener saldo negativo a ligeramente positivo.

\subsection{Variación en las tasas de migración}

La variación en las tasas de migración entre los periodos de referencia, 1980-1985 y 1995-2000, se resume en la tabla 8 . 
Desarrollo, subdesarrollo y migraciones internacionales a comienzos del siglo xxl

Tabla 8. Variación de las tasas de transferencia de población entre regiones y macroregiones del mundo (1980-1985 a 1995-2000)

\begin{tabular}{|c|c|c|c|c|c|}
\hline $\begin{array}{c}\text { Macroregiones } \\
\text { regiones } \\
\text { del mundo }\end{array}$ & $\begin{array}{c}\text { Tasa trans- } \\
\text { ferencia } \\
\text { anual } \\
\text { (\%. hab.) } \\
1980-1985\end{array}$ & $\begin{array}{c}\text { Tasa trans- } \\
\text { ferencia } \\
\text { anual } \\
(\% \text { hab.) } \\
1995-2000\end{array}$ & $\begin{array}{c}\text { Macroregiones } \\
\text { regiones } \\
\text { del mundo }\end{array}$ & $\begin{array}{c}\text { Tasa trans- } \\
\text { ferencia } \\
\text { anual } \\
(\% \text { hab.) } \\
1980-1985\end{array}$ & $\begin{array}{c}\text { Tasa trans } \\
\text { ferencia } \\
\text { anual } \\
\text { (\%o hab.) } \\
1995-2000\end{array}$ \\
\hline África & $-0,24$ & $-1,13$ & Europa & $-0,10$ & 1,93 \\
\hline África oriental & $-0,31$ & $-0,18$ & Europa oriental & $-0,08$ & 0,80 \\
\hline África central & 0,04 & $-2,34$ & Europa septentrional & $-0,36$ & 1,40 \\
\hline África septentrional & $-0,80$ & $-0,39$ & Europa meridional & $-0,35$ & 1,50 \\
\hline África meridional & $-0,04$ & 0,90 & Europa occidental & 0,17 & 3,09 \\
\hline África occidental & 0,14 & $-2,64$ & $\begin{array}{l}\text { América Latina y } \\
\text { el Caribe }\end{array}$ & $-0,85$ & $-1,03$ \\
\hline Asia & $-0,03$ & $-0,38$ & Caribe & $-3,50$ & $-1,80$ \\
\hline China & 0,02 & 0,22 & Centroamérica & $-1,43$ & $-3,34$ \\
\hline Japón & $-0,01$ & 0,95 & $\begin{array}{l}\text { América del Sur } \\
\text { tropical }\end{array}$ & $-0,32$ & $-0,28$ \\
\hline Resto Asia oriental & 0,05 & $-0,07$ & $\begin{array}{l}\text { América del Sur } \\
\text { templada }\end{array}$ & $-0,38$ & 1,04 \\
\hline \multicolumn{6}{|l|}{ Asia } \\
\hline centromeridional & $-0,04$ & $-1,13$ & América del Norte & 1,90 & 3,93 \\
\hline Asia sudoriental & $-0,51$ & $-1,09$ & Oceanía & 2,61 & 3,80 \\
\hline \multirow[t]{2}{*}{ Asia occidental } & 1,25 & 2,55 & Australia-Nueva & & \\
\hline & & & Zelanda & 4,33 & 4,60 \\
\hline Antigua URSS & 0,05 & 1,59 & $\begin{array}{l}\text { Melanesia, Micro. } \\
\text { y Polinesia }\end{array}$ & $-3,12$ & 0,50 \\
\hline
\end{tabular}

Elaboración propia.

Por macroregiones, en lo que respecta a la tasa de transferencia anual positiva, América del Norte incrementa su tasa de 1,90\%/hab. a $3,93 \%$ /hab.; Oceanía de 2,61\%/hab. a 3,8\%/hab.; la ex URSS de $0,05 \% /$ hab. a $1,59 \% /$ hab. Pero, sin duda, el cambio fundamental lo tiene Europa que pasa de tener una tasa negativa a presentar, en conjunto, una tasa de transferencia positiva de 1,93\%/hab.

En las tasas de transferencia negativas, África, con una tasa de $-1,13 \%$ o/hab., supera a América Latina que con $-0,85 \%$ /hab. ocupaba el primer puesto en el periodo 1980-1985, viendo incrementada esta última macroregión su tasa a $-1,03 \%$ /hab. Asia también ha aumentado entre los dos periodos su tasa de transferencia negativa, que de $-0,03 \% /$ hab. pasa a $-0,38 \% /$ hab. Ello significa que África ha multiplicado su tasa de transferencia por 4,6; Asia, por 12,6, y América Latina, por 1,2.

No obstante, por grandes regiones, estos cambios presentan sus diferencias que se resumen de la siguiente manera. En África, las dos regio- 
nes que experimentan una transformación más profunda son África central y occidental; África central pasa incluso de tener una pequeña tasa positiva de 0,04\%ohab. en el periodo 1980-1985 a una tasa negativa de $2,38 \%$ hab.; ello se debe a que estas dos regiones son las que han visto en mayor medida frustradas sus expectativas de desarrollo por las guerras regionales y la corrupción de los gobiernos. África septentrional ve ligeramente disminuida su tasa emigratoria ${ }^{10}$; África oriental reduce ligeramente su tasa debido a un proceso de integración económica regional. El cambio más importante lo ha experimentado África meridional, que se ha convertido en un centro receptor de inmigrantes, debido a la estabilidad de la región tras el cambio democrático en Sudáfrica y la senda del desarrollo económico emprendida en ese país.

En Asia, China incrementa ligeramente su tasa inmigratoria debido a la profunda transformación económica de las zonas especiales de economía de mercado que genera migración de retorno. Japón, aunque pasa de una tasa negativa a positiva, ésta todavía es muy pequeña para su nivel de desarrollo económico. Asia occidental incrementa de 1,25\%/hab. a $2,55 \% /$ hab. su tasa de inmigración; en ello tiene que ver la evolución que han sufrido el resto de regiones de Asia, particularmente la centromeridional y la sudoriental, que registran tasas de $-1,13 \%$ o/hab. y $-1,09 \% / \mathrm{hab}$., respectivamente, lo que ha podido favorecer la inmigración en Asia occidental, China y Japón; no obstante, la mayor parte de estos emigrantes se marcha fuera del continente asiático. La región que constituye la antigua URSS ha visto incrementada su tasa inmigratoria, debido también a los aportes de las regiones asiáticas.

Europa, en el periodo 1995-2000, tiene todas sus regiones con una tasa de transferencia positiva; la occidental, septentrional y meridional han experimentado entre los dos periodos de referencia una transformación inmigratoria sin precedentes. El tradicional destino de América del Norte ha pasado a ser compartido por estas regiones de Europa; el incremento de la tasa emigratoria en las regiones africanas y asiáticas ha hecho de Europa un destino de los emigrantes de estas regiones.

En América Latina y el Caribe se han producido cambios diferentes; mientras que Centroamérica incrementa considerablemente su tasa emigratoria, de $-1,43 \% /$ hab. al $-3,34 \%$ /hab., el Caribe la reduce de manera importante; la explicación para el Caribe es la importante revalorización

${ }^{10}$ Esta reducción se debe más a la moderación de países como Argelia y Egipto, pues Marruecos es un país que aumenta su tasa emigratoria. 
turística de esa región; en cambio, Centroamérica es una región donde las guerras, el posterior fracaso económico, así como las numerosas redes de migración asentadas en Estados Unidos, han hecho de este país el destino de la migración centroamericana. América del sur tropical reduce la emigración y América del sur templada se convierte en centro receptor de migración; este cambio positivo puede deberse a una mayor integración de los países de estas regiones, con Brasil como centro económico más importante y en pleno crecimiento.

América del Norte tiene el incremento más importante de inmigración de todas las macroregiones con saldo positivo, siendo destino de la mayoría de los migrantes Latinoamericanos y asiáticos que deciden cambiar de continente. En Oceanía, la región de Australia-Nueva Zelanda mantiene en los periodos de referencia su elevada tasa de inmigración. El resto de Oceanía pasa a convertirse en centro receptor de migración; en ello tiene que ver una economía relativamente mejor que la de los países de las regiones asiáticas sudoriental y centromeridional, de donde proceden la mayor parte de los inmigrantes.

En el conjunto mundial, la tasa de transferencia de las regiones en el periodo 1995-2000 fue de 0,61 migrantes por mil personas, siendo de $0,45 \% / \mathrm{hab}$. entre macroregiones y del $0,16 \% / \mathrm{hab}$. dentro de las macroregiones. En cifras absolutas supone que el número total de emigrantes entre grandes regiones de la Tierra fue de 18,3 millones ${ }^{11}$; de ellos 13,7 cambiaron de macroregión y 4,6 millones se desplazaron dentro de las macroregiones. En comparación con el periodo 1980-1985 significa que el saldo migratorio entre grandes regiones se ha incrementado en un $449 \%$, el saldo entre macroregiones en un $468 \%$ y el saldo interno de las macroregiones en un $407 \%$. En la tabla 9 , se puede ver el resumen mundial de los dos periodos.

\footnotetext{
11 El saldo migratorio total entre países evidentemente fue mayor: en el periodo 1995-2000 fue de 28 millones, con una tasa de transferencia anual de $0,96 \%$ ohab.
} 
Tabla 9. Resumen y comparación de saldos y tasas mundiales de transferencia de población en los periodos 1980-1985 y 1995-2000

\begin{tabular}{|c|c|c|c|c|c|c|}
\hline Ámbitos & $\begin{array}{c}\text { Saldo } \\
\text { migratorio } \\
1980-1985 \\
\text { (5 años } \\
\text { miles) }\end{array}$ & $\begin{array}{c}\text { Saldo } \\
\text { migratorio } \\
1995-2000 \\
\text { (5 años } \\
\text { miles) }\end{array}$ & $\begin{array}{c}\text { Tasa } \\
\text { transfe- } \\
\text { rencia } \\
\text { anual } \\
\text { (\%o hab.) } \\
\text { 1980-1985 }\end{array}$ & $\begin{array}{c}\text { Tasa } \\
\text { transfe- } \\
\text { rencia } \\
\text { anual } \\
(\% \text { hab.) } \\
1995-2000\end{array}$ & $\begin{array}{c}\text { Incremento } \\
\text { porcentual } \\
\text { de los } \\
\text { saldos } \\
\text { migratorios } \\
\text { entre } \\
\text { 1980-1985 } \\
y \\
1995-2000\end{array}$ & $\begin{array}{c}\text { Incremento } \\
\text { porcentual } \\
\text { de las } \\
\text { tasas de } \\
\text { transferen- } \\
\text { cia entre } \\
1980-1985 \\
y \\
1995-2000\end{array}$ \\
\hline De las regiones & 4.078 & 18.292 & 0,17 & 0,61 & $448,6 \%$ & $359,7 \%$ \\
\hline $\begin{array}{l}\text { Entre macroregiones } \\
\text { Interna de las } \\
\text { macroregiones }\end{array}$ & 2.943 & 13.675 & 0,12 & 0,45 & $464,7 \%$ & $372,6 \%$ \\
\hline Ámbitos & $\%$ Saldo & $\%$ Saldo & $\%$ Tasa & $\%$ Tasa & & \\
\hline $\begin{array}{l}\text { De las regiones } \\
\text { Entre macroregiones } \\
\text { Interna de las } \\
\text { macroregiones }\end{array}$ & $\begin{array}{r}100,0 \% \\
72,2 \%\end{array}$ & $\begin{array}{r}100,0 \% \\
74,8 \%\end{array}$ & $\begin{array}{r}100,0 \% \\
72,2 \%\end{array}$ & $\begin{array}{r}100,0 \% \\
74,8 \%\end{array}$ & & \\
\hline
\end{tabular}

Referencia: Cuadros 6 y 7 . Elaboración propia.

\section{RELACIÓN DE LOS MOVIMIENTOS MIGRATORIOS CON LOS CONDICIONANTES SOCIOECONÓMICOS}

Para conocer en qué grado, en el conjunto mundial, los datos de transferencia de población pueden estar explicados por condicionantes socioeconómicos objetivos, se han puesto en relación las tasas de transferencia de las regiones del mundo del periodo 1995-2000 con las notaciones factoriales del factor socioeconómico analizado en el apartado 3 , promediadas éstas por regiones mundiales, datos en ambos casos de los últimos años del siglo Xx. En el cuadro 10, se han ordenado las notaciones promediadas por regiones, clasificando las mismas en los cuatro modelos socioeconómicos ya vistos por países en el apartado 3 .

Las regiones que se identifican, según el valor de las notaciones promediadas, con el modelo 1, son todas las de Europa, América del Norte, Japón y la de Australia-Nueva Zelanda. Las del modelo 2, América del Sur templada, la antigua URSS, Asia oriental sin Japón e incluido China, el Caribe y América del Sur tropical, si bien en este modelo se debe diferen- 
ciar entre América del Sur templada y la antigua URSS ${ }^{12}$, por un lado, y el resto de regiones, por otro. El modelo 3 está compuesto por las regiones de Asia occidental, Centroamérica, Asia sudoriental, África septentrional, África meridional, Melanesia-Micronesia-Polinesia y Asia centro-meridional. Las regiones del modelo 4 son las más deprimidas de África, a saber, la central, occidental y la oriental. Si tomamos los modelos más extremos, el modelo 1 puede considerarse estructural, ya que a partir de sus propios recursos no puede cambiar la estructura demográfica; el desequilibrio estructural de los modelos 3 y 4 habría que entenderlo como la incapacidad para cambiar la situación de subdesarrollo a partir de sus propios recursos. El modelo 2 estaria en una posición intermedia.

Tabla 10. Correlación por regiones del mundo entre la tasa de transferencia y las notaciones del factor socioeconómico (1995-2000)

\begin{tabular}{|c|c|c|c|}
\hline $\begin{array}{l}\text { Regiones del mundo } \\
\text { ordenadas según } \\
\text { promedio notaciones } \\
\text { factoriales del factor } \\
\text { socioeconómico }\end{array}$ & $\begin{array}{l}\text { Promedio } \\
\text { notaciones } \\
\text { factor } \\
\text { socioeco- } \\
\text { nómico }\end{array}$ & $\begin{array}{l}\text { Tasa } \\
\text { transferen- } \\
\text { cia anual } \\
\text { (\%o hab.) } \\
1995-2000\end{array}$ & Modelos socioeconómicos \\
\hline $\begin{array}{l}\text { Japón } \\
\text { Europa occidental } \\
\text { Europa septentrional } \\
\text { América del Norte } \\
\text { Australia-Nueva Zelanda } \\
\text { Europa oriental } \\
\text { Europa meridional }\end{array}$ & $\begin{array}{l}-1,63 \\
-1,57 \\
-1,40 \\
-1,29 \\
-1,21 \\
-1,09 \\
-1,00\end{array}$ & $\begin{array}{l}0,91 \\
3,05 \\
1,46 \\
3,87 \\
4,46 \\
0,78 \\
1,51\end{array}$ & $\begin{array}{l}\text { Modelo } 1 \text { (CENTRO): (notaciones -1,69 } \\
\text { a -1), de } 39 \text { paises del mundo con } \\
\text { desarrollo o moderado desarrollo } \\
\text { socioeconómico y situación } \\
\text { demográfica estancada. } \\
\text { Regiones del mundo potencialmente } \\
\text { receptoras de emigración exterior. }\end{array}$ \\
\hline $\begin{array}{l}\text { América del Sur templada } \\
\text { Antigua URSS } \\
\text { Resto Asia oriental } \\
\text { Caribe } \\
\text { China } \\
\text { América del Sur tropical }\end{array}$ & $\begin{array}{l}-0,89 \\
-0,69 \\
-0,41 \\
-0,18 \\
-0,07 \\
-0,01\end{array}$ & $\begin{array}{r}1,10 \\
1,58 \\
-0,11 \\
-1,85 \\
0,22 \\
-0,27\end{array}$ & $\begin{array}{l}\text { Modelo } 2 \text { (SEMIPERIFERIA): } \\
\text { (notaciones }-0,99 \text { a } 0 \text { ), de } 42 \text { paises } \\
\text { del mundo con moderado desarrollo } \\
\text { socioeconómico y situación demográfica } \\
\text { de moderada a dinámica. } \\
\text { Regiones del mundo, potencialmente, } \\
\text { moderadamente receptoras o emisoras } \\
\text { de migración. }\end{array}$ \\
\hline $\begin{array}{l}\text { Asia occidental } \\
\text { Centroamérica } \\
\text { Asia sudoriental } \\
\text { África septentrional } \\
\text { África meridional }\end{array}$ & $\begin{array}{l}0,06 \\
0,19 \\
0,29 \\
0,41 \\
0,46\end{array}$ & $\begin{array}{r}2,51 \\
-3,31 \\
-1,09 \\
-0,39 \\
0,95\end{array}$ & $\begin{array}{l}\text { Modelo } 3 \text { (PERIFERIA 1): (notaciones } \\
0,01 \text { a 1), de } 52 \text { países del mundo con } \\
\text { moderado desarrolio o subdesarrollo } \\
\text { socioeconómico y situación demográfica } \\
\text { dinámica. }\end{array}$ \\
\hline
\end{tabular}

12 En la ex URSS, los países asiáticos no se pueden considerar desarrollados; en cambio, Rusia se considera un pais industrial. Pero en el promedio de las notaciones el valor regional es superior a $-1(-0,69)$. 
Tabla 10. Correlación por regiones del mundo entre la tasa de transferencia y las notaciones del factor socioeconómico (1995-2000) (continuación)

\begin{tabular}{|c|c|c|c|}
\hline $\begin{array}{l}\text { Regiones del mundo } \\
\text { ordenadas según } \\
\text { promedio notaciones } \\
\text { factoriales del factor } \\
\text { socioeconómico }\end{array}$ & $\begin{array}{l}\text { Promedio } \\
\text { notaciones } \\
\text { factor } \\
\text { socioeco- } \\
\text { nómico }\end{array}$ & $\begin{array}{c}\text { Tasa } \\
\text { transferen- } \\
\text { cia anual } \\
\text { (\% hab.) } \\
1995-2000\end{array}$ & Modelos socioeconómicos \\
\hline $\begin{array}{l}\text { Melanesia, Micronesia y } \\
\text { Polinesia } \\
\text { Asia centromeridional }\end{array}$ & $\begin{array}{l}0,87 \\
0,89\end{array}$ & $\begin{array}{r}0,63 \\
-1,12\end{array}$ & $\begin{array}{l}\text { Regiones del mundo, potencialmente, } \\
\text { moderadamente emisoras de migración } \\
\text { entre regiones y fuertemente emisoras } \\
\text { de emigración fuera de su macroregión. }\end{array}$ \\
\hline $\begin{array}{l}\text { África central } \\
\text { África occidental } \\
\text { África oriental }\end{array}$ & $\begin{array}{l}1,04 \\
1,17 \\
1,21\end{array}$ & $\begin{array}{l}-2,31 \\
-2,60 \\
-0,18\end{array}$ & $\begin{array}{l}\text { Modelo } 4 \text { (PERIFERIA 2): (notaciones } \\
1,01 \text { a } 1,71 \text { ), de } 37 \text { paises del mundo } \\
\text { con subdesarrollo socioeconómico y } \\
\text { situación demográfica muy dinámica. } \\
\text { Regiones del mundo, potencialmente, } \\
\text { fuertemente emisoras de emigración } \\
\text { fuera de su macroregión. }\end{array}$ \\
\hline
\end{tabular}

Correlación: $\mathbf{r}=$

$-0,7$

Elaboración propia.

Como se puede comprobar en el cuadro 10, existe una correspondencia importante, en cada región mundial, entre el valor de la notación del modelo socioeconómico y las tasas de transferencia de población, siendo esta relación inversa, es decir, que, en general, a las regiones socioeconómicamente desarrolladas les corresponde una cuota de inmigración y, a la inversa, a las regiones socioeconómicamente subdesarrolladas les corresponde una cuota de emigración ${ }^{13}$. En el gráfico 1, se establece una línea de delimitación entre el desarrollo y el subdesarrollo, la inmigración y la emigración.

La relación entre el valor del desarrollo socioeconómico y las tasas de transferencia migratoria para el quinquenio 1995-2000, que se explica matemáticamente al nivel mundial en un: $\left(-0,7^{2 \times} \times 100\right)=49 \%$, viene a decir que la respuesta migratoria a los condicionantes socioeconómicos, establecidos en el factor que resumen las 14 variables, es homogénea; y se puede afirmar que, a firiales del siglo $\mathrm{xx}$, existe una relación directa en todo el mundo entre condicionantes socioeconómicos y migración regional.

${ }^{13}$ La región que no guarda correspondencia alguna es Asia occidental, por las características especiales de los países petrolíferos, de subdesarrollo de la población y fuerte demanda de trabajo dentro de la región. 


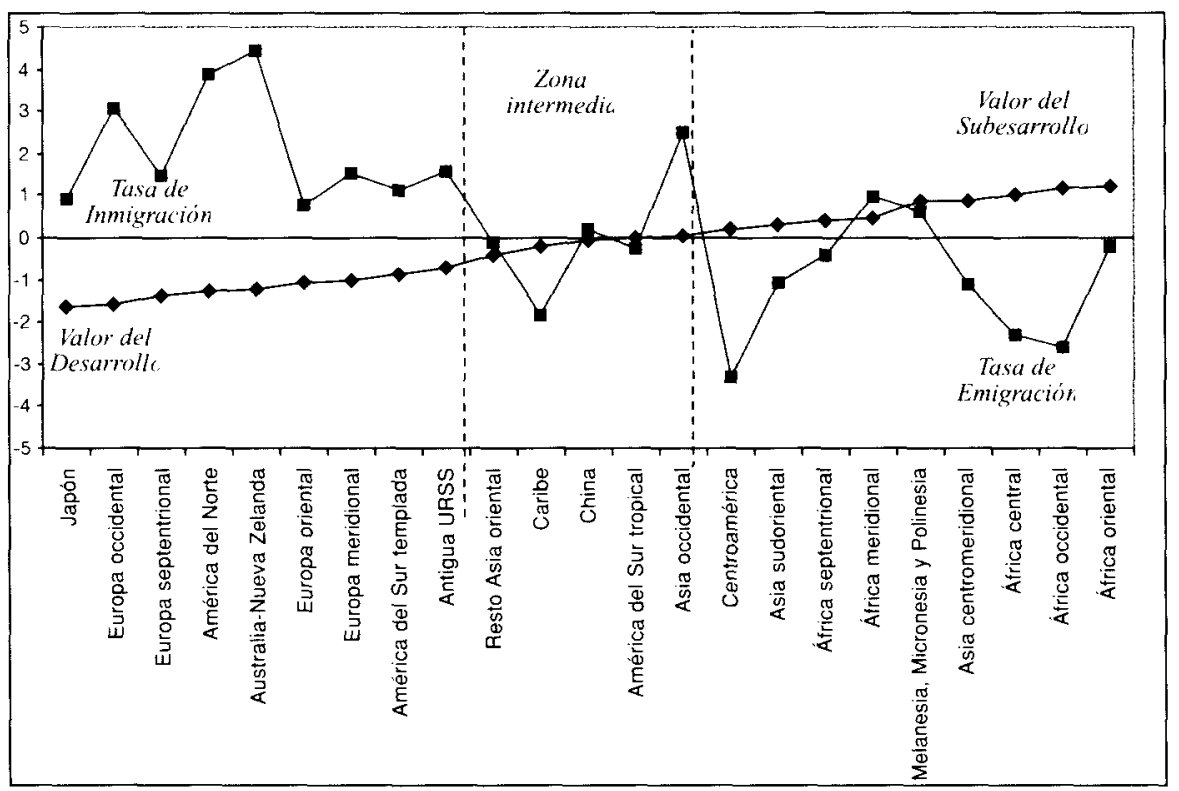

Gráfico 1. Delimitación del desarrollo socioeconómico y la migración por regiones del mundo. Elaboración propia.

Pero esto, que parece obvio, es una novedad que aparece en las migraciones de finales del siglo $\mathrm{XX}$, pues, si extrapolamos las diferencias socioeconómicas regionales del mundo en el periodo $1995-2000^{14}$ al quinquenio $1980-1985$ y las relacionamos con las tasas de transferencia de población de esos años, la correlación hallada es de $-0,3\left(-0,3^{2} \times 100\right)=12 \%$. Esta evolución de un $12 \%$ a un $49 \%$ en la respuesta migratoria de las grandes regiones a los condicionantes socioeconómicos, sin que hayan cambiado sustancialmente los mismos, da a entender:

1. Que en el periodo 1980-1985 los desequilibrios socioeconómicos de los países de las regiones periféricas no se traducian en una respuesta homogénea migratoria hacia las regiones del centro desarrollado.

2. Que la persistencia de los condicionantes socioeconómicos, de las últimas décadas del siglo $\mathrm{xx}$, en el marco nacional de las regiones perifé-

14 Si bien los valores de las 14 variables utilizadas en el análisis factorial no son extrapolables, las diferencias relativas socioeconómicas de las regiones del mundo puede entenderse que sí, pues estructuralmente estas diferencias son históricas $y$, a pesar de los cambios internos de las regiones, no han cambiado sustancialmente en los 15 años de diferencia. 
ricas está acrecentando la búsqueda de soluciones en la emigración a las regiones del centro desarrollado.

3. Que el mundo se percibe cada vez más globalizado, o lo que es lo mismo, que las regiones tienden a ser menos particulares ante los desequilibrios socioeconómicos del mundo.

4. Que la respuesta migratoria a las diferencias socioeconómicas regionales del mundo es históricamente dinámica.

Tabla 11

\begin{tabular}{lcc}
\hline \multicolumn{1}{c}{ Regiones } & Notación socioeconómica & Tasa de transferencia \\
\hline África meridional & 0,46 & 0,95 \\
África oriental & 1,21 & $-0,18$ \\
Asia occidental & 0,06 & 2,51 \\
Japón & $-1,63$ & 0,91 \\
Caribe & $-0,18$ & $-1,85$ \\
Centroamérica & 0,19 & $-3,31$ \\
Australia -Nueva Zelanda & $-1,21$ & 4,46 \\
Melanesia, Micronesia y Polinesia & 0,87 & 0,63 \\
\hline
\end{tabular}

De todas maneras existen diferencias que convienen apuntar. Si tomamos el periodo 1995-2000, hay algunas regiones que la notación del desequilibrio socioeconómico escasamente se corresponde con la tasa de transferencia de población, positiva o negativa.

En Africa, África Oriental, con una notación importante de desequilibrio socioeconómico, tiene una tasa de emigración relativamente pequeña, y África Meridional, siendo una región subdesarrollada, presenta una tasa de inmigración; ello se explica porque los países de África Oriental están muy integrados en su región, y en África Meridional, Sudáfrica es un país que se constituye como centro de atracción. En América, Centroamérica y el Caribe, con unas notaciones de desequilibrio moderadas, presentan tasas de emigración altas; ello se explica porque son regiones que están totalmente extravertidas hacia Norteamérica. En Asia, Japón y Asia Occidental presentan respuestas contrarias entre sus desequilibrios internos y su tasa migratoria; a Japón le debiera corresponder una tasa de inmigración mayor y a Asia Occidental menor; estas diferencias se explican, en el caso de Japón, por su carácter de país cerrado y, en el caso de Asia Occidental, por la atracción migratoria que ejercen los países petrolíferos. En Oceanía, a Australia-Nueva Zelanda le debiera corresponder una tasa de inmigración menor, pero tiene la más alta de los países desarrollados; ello es debido a la presión migratoria asiática, presión que también se manifiesta 
en el resto de Oceanía, pues con una notación de subdesarrollo presenta una tasa moderada de inmigración ${ }^{15}$.

En resumen, las regiones emisoras más importantes del mundo y que irrumpen con fuerza en la lista de regiones con saldos emigratorios, tanto por su elevada tasa como por su fuerte evolución emigratoria, son África central y occidental, Asia centromeridional y sudoriental, y Centroamérica. El peso específico de población de estas regiones se puede ver en la tabla 12.

Tabla 12. Población de las regiones del mundo emisoras de migración en el 2000

\begin{tabular}{lclr}
\hline $\begin{array}{l}\text { Regiones moderadamente } \\
\text { emisoras de migración }\end{array}$ & $\begin{array}{c}\text { Millones } \\
2000\end{array}$ & $\begin{array}{c}\text { Regiones fuertemente } \\
\text { emisoras de migración }\end{array}$ & $\begin{array}{c}\text { Millones } \\
2000\end{array}$ \\
\hline África oriental & 244,858 & África central & 95,052 \\
África septentrional & 172,973 & África occidental & 219,933 \\
Resto Asia oriental & 73,545 & Asia centromeridional & $1.434,603$ \\
Caribe & 31,796 & Asia sudoriental & 517,328 \\
América del Sur tropical & 288,739 & Centroamérica & 135,221 \\
\hline TOTAL & $\mathbf{8 1 1 , 9 1 1}$ & & $\mathbf{2 . 4 0 2 , 1 3 7}$ \\
\hline
\end{tabular}

Elaboración propia.

De los 6.055,053 millones de personas que habitaban el mundo en el año 2000 , más de la mitad de la población del mundo (un 53\%) vivía en regiones emisoras de migración neta. De este porcentaje el 13,4\% vivía en regiones moderadamente emisoras de migración y un $39,6 \%$ en regiones fuertemente emisoras de migración. Esta enorme masa de población está experimentando una profunda transformación en su forma de pensar en lo que se refiere al marco político-económico para resolver sus expectativas de vida individuales y sociales; es decir, el marco nacional deja de ser la referencia para su posible desarrollo y queda como única opción la voluntad de emigrar, en la mayoría de los casos, con carácter definitivo.

Ésta es la característica esencial de las migraciones que van a presidir como mínimo las primeras décadas del siglo XXI; una emigración que nace no sólo del fracaso del desarrollo de sus países de origen, sino también y sobre todo, y esto es lo más importante, de la percepción de ese fracaso. Esto, a su vez, constituye un camino sin retorno en la forma del pensa-

${ }^{15}$ La correlación, no teniendo en cuenta estas regiones, pasa de $r=0,7(49 \%)$ a $r=0,81$ $(65 \%)$. 
miento colectivo, la nación deja de ser referencia para el desarrollo, convirtiéndose, en esta percepción globalizada, en un ámbito de confinamiento a la miseria. La solución que ven millones de personas es la emigración a los grandes centros de desarrollo. Tal vez, China sea el país que mantiene un pensamiento nacional y de desarrollo más fuerte; pero ello se debe a su tradición nacionalista, a los éxitos económicos de las dos últimas décadas del siglo $x x$ y a su peculiar régimen político.

\section{ESTIMACIÓN AL 2025 DE LOS MOVIMIENTOS MIGRATORIOS MUNDIALES}

Teniendo en cuenta la variación de los saldos migratorios entre los periodos 1980-1985 y 1995-2000, se ha estimado la tendencia de los mismos hasta el año 2025 (gráfico número 2). En el mundo los emigrantes que podrían cambiar de región pasarían de 4,1 millones en 1980-1985 a 43,3 millones en el periodo 2020-2025, siendo el saldo migratorio entre regiones del mundo de 210,3 millones de personas en los 45 años transcurridos. Los emigrantes que en 1980-1985 cambiaron de macroregión fueron 2,9 millones y podrian ser 32 millones en 2020-2025, produciéndose en los 45 años un saldo migratorio de 156,2 millones.

Teniendo en cuenta la estimación de población mundial realizada por la ONU para el 2025, el porcentaje de emigrantes internacionales podría ascender al 2,7\% del total; de este porcentaje el 2,0\% habría cambiado de macroregión mundial y el $0,7 \%$ se habría desplazado dentro de su macroregión. Esta cantidad globalmente no parece importante; pero, si se tiene en cuenta el volumen de población estimado para Europa para el año 2025, el porcentaje de los inmigrantes llegados en los 45 años supondrá el $11,87 \%$ del total de la población europea ( $18,03 \%$ en Europa Occidental); en América del Norte este porcentaje podría ascender al $17,66 \%$ de su población total. Estas cifras indican que las regiones del centro desarrollado van a experimentar una importante transformación en la estructura de su población debido a los aportes demográficos procedentes de los países subdesarrollados.

Evidentemente, la tendencia de crecimiento de los movimientos migratorios entre regiones y macroregiones del mundo, tal y como muestran el gráfico 2 y 3 , no es ilimitada, por lo que el descenso de la curva podría llegar antes del 2025; pero, en la actualidad, nada indica que esta tendencia pueda frenarse. De mantenerse las actuales cifras, las migraciones internacionales en la tercera década del siglo XXI constituiría el acontecimiento que más profundamente estaría transformando el mundo. 


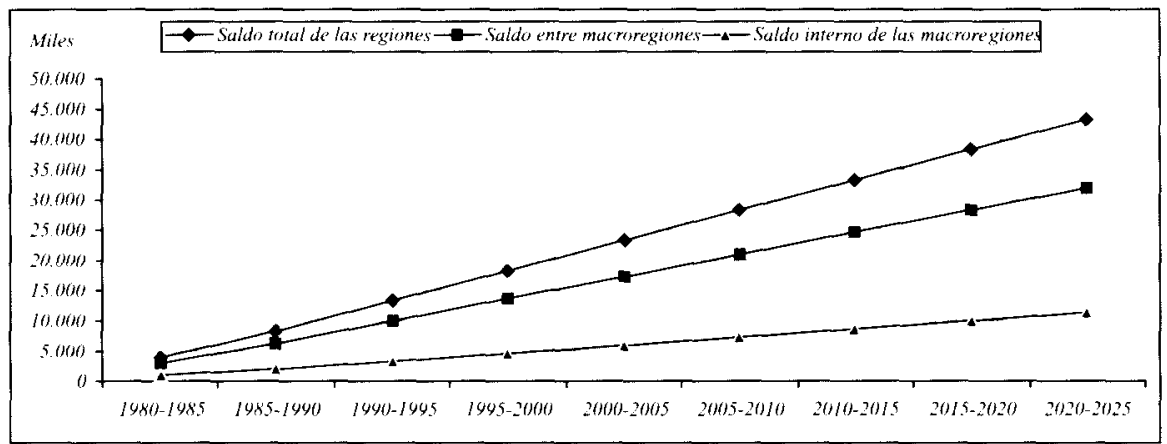

Gráfico 2. Tendencia de la proyección de la migración del mundo (1980-2025).

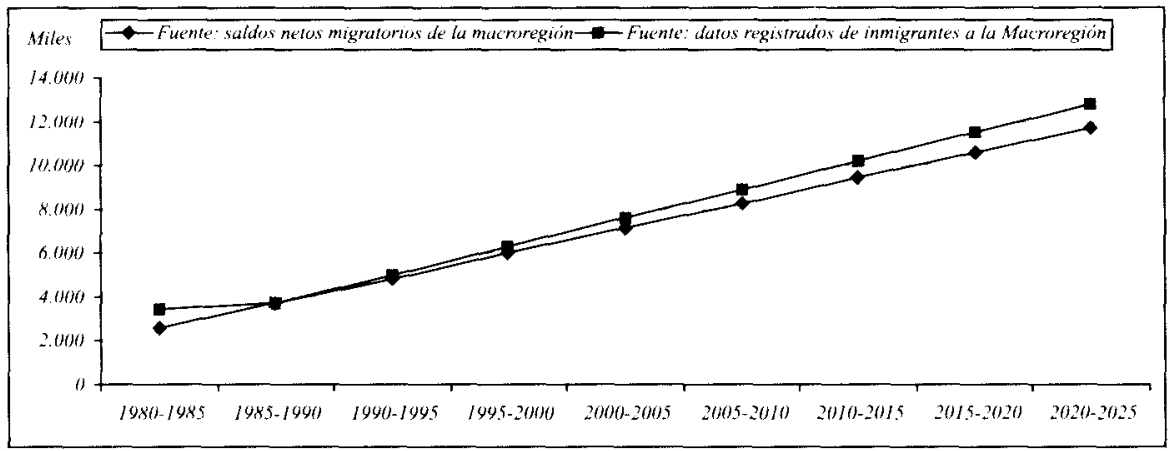

Gráfico 3. Tendencia de la proyección de la migración en América del Norte según fuente de registro de inmigrantes y de saldos netos de migración (1980-2025).

\begin{tabular}{lccccccccc}
\hline $\begin{array}{l}\text { América del Norte } \\
\text { (miles) }\end{array}$ & $\begin{array}{l}1980- \\
1985\end{array}$ & $1985-$ & $1990-$ & $1995-$ & $2000-$ & $2005-$ & $2010-$ & $2015-$ & $2020-$ \\
& 1995 & 2000 & 2005 & 2010 & 2015 & 2020 & 2025 \\
\hline $\begin{array}{l}\text { Fuente: registro } \\
\text { de inmigrantes }\end{array}$ & 3.395 & 3.718 & 5.019 & 6.320 & 7.622 & 8.923 & 10.224 & 11.525 & 12.826 \\
$\begin{array}{l}\text { Fuente: saldos } \\
\text { netos migratorios }\end{array}$ & 2.561 & 3.704 & 4.847 & 5.990 & 7.133 & 8.276 & 9.419 & 10.562 & 11.705
\end{tabular}

Los datos proyectados son desde el periodo 2000-2005 inclusive.

Elaboración propia.

De todas maneras, es más que previsible que este incremento migratorio no va a resolver los graves problemas socioeconómicos que están impulsando y van a seguir impulsando a millones de personas a emigrar, pues la desproporción de población entre los centros emisores y los receptores es de tal magnitud, que es impensable un vaciado de población sustancial de las regiones emisoras; $y$ es igualmente impensable que las regiones recep- 
toras puedan soportar un aumento indefinido del volumen de inmigrantes. Pero esta consideración es ajena a la voluntad de quienes quieren emigrar. Por ello, la presión sobre los centros receptores de inmigración va a ser creciente. Y esta presión podría y debería empujar a los países desarrollados a poner en marcha iniciativas que mejoren tanto las condiciones económicas de los países pobres como las relaciones comerciales con ellos.

\section{CONCLUSIÓN}

Las causas objetivas de las migraciones se basan, en primer lugar, en un desequilibrio regional o nacional interno, es decir, en un desequilibrio entre la situación de la población y las expectativas de desarrollo económico. Esta situación interna se complementa con el desequilibrio a escala mundial entre países desarrollados y países subdesarrollados. Este doble desequilibrio es el que genera los condicionantes objetivos que desencadenan las migraciones desde los países menos desarrollados a los más desarrollados.

A las causas objetivas se suman las subjetivas. Éstas nacen de la persistencia en el tiempo de los desequilibrios internos nacionales y la desesperanza de los ciudadanos en resolverse sus problemas dentro del espacio nacional y en un futuro inmediato. A la vez, la creciente percepción de un mundo globalizado contribuye a considerar el planeta como un único ámbito de referencia político-económica, por lo que se termina considerando a la emigración a los centros desarrollados como la única vía de cumplir las expectativas de desarrollo de los ciudadanos, minimizando el problema de los controles fronterizos.

La interactuación de ambos grupos de causas no es cuantificable, pero sí es irreversible. Y se produce en sectores cada vez más numerosos de población, cuyo creciente desánimo les empuja a emigrar. La diferencia respecto a otras migraciones del pasado es que nunca hasta ahora la mayoría de la población del mundo ha estado sujeta a motivaciones migratorias tan fuertes como las que se adivinan para el siglo XXI.

Así pues, las migraciones transnacionales del siglo XXI no van a seguir las pautas de las migraciones del siglo xIx de Europa a América, ni tampoco van a estar referidas a un periodo histórico concreto, como ocurrió con las migraciones de la posguerra de la Segunda Guerra Mundial. Las migraciones actuales, que tienen su origen en los fuertes desequilibrios existentes dentro de los países subdesarrollados y en los desequilibrios entre regiones ricas y pobres de la Tierra, son movimientos migratorios estructu- 
rales y mundiales. Al no responder a un proceso histórico coyuntural, estas migraciones, una vez iniciadas, pueden mantenerse vivas por un tiempo indefinido. Si bien las personas que deciden emigrar constituyen todavía porcentajes muy pequeños de la población de los países emisores, el fracaso del desarrollo en esos países se ha convertido en un potente factor de futuras migraciones; al mismo tiempo, el éxito de los que emigraron funciona igualmente como un factor de estímulo a posibles emigrantes.

En el pasado, las fronteras fueron barreras relativamente eficaces para controlar los movimiento de personas. Hoy esas barreras son insuficientes para frenar el incontenible deseo de millones de personas de mejorar sus expectativas de vida. La magnitud del problema requiere una profunda reorientación del desarrollo económico y social a escala mundial, de tal manera que permita devolver el deseo de seguir viviendo en sus lugares de residencia a los millones de personas que piensan en la emigración como única solución a su precaria o insostenible situación.

\section{BIBLIOGRAFIA}

Blanco, C. (2000): Las migraciones contemporáneas. Ed. Alianza, Madria, pág. 202.

CENTRO DE LA NACIONES UNIDAS PARA lOS ASENTAMIENTOS HuMANOS (1989): Informe mundial sobre asentamientos humanos, 1986. Instituto del Territorio y Urbanismo, Madrid, pág. 344.

Galbraith, J. K. (1989): Historia de la economía. Ed. Ariel, Barcelona, pág. 327.

- (1993): Introducción a la economia. Ed. Grijatbo, Barcelona, pág. 234

George, S. (1990): La trampa de la deuda. Ed. lepala, Madrid, pág. 377.

Grimal, H. (1989): Historia de las descolonizaciones del siglo XX. Ed. lepala, Madrid, pág. 408.

Gunder Frank, A. (1991): El subdesarrollo del desarrollo: un ensayo autobiográfico. Ed. lepala, Madrid, pág. 137.

Hobsbawm, E. (1995): Historia del siglo xx. Ed. Crítica, Barcelona, pág. 615.

- (2000): Entrevista sobre el siglo xxı. Ed. Crítica, Barcelona, pág. 220.

LANDES, D. (2000): La riqueza y la pobreza de las naciones. Ed. Crítica. Barcelona, pág. 604.

LIVI-BACCI, M. (1990): Historia mínima de la población mundial. Ed. Ariel, Barcelona, pág. 208.

MALGESINI, G./GIMÉNEZ, C. (2000): Guia de conceptos sobre migraciones; racismo e interculturalidad. Consejería de Educación de la Comunidad de Madrid. Madrid, pág. 406.

Malthus, R. (1979): Primer ensayo sobre la población. Ed. Alianza, Madrid, pág. 318.

Martinez, J.; VIDAL, J. M. y Otros (1995): Economía Mundial. Ed. McGraw-Hill/Interamericana de España, S.A., Madrid, pág. 480.

MÉNDEZ, R. y MOLINERO, F. (1998): Espacios y sociedades. Introducción a la geografía regional del mundo. Ed. Ariel, Barcelona, pág. 675.

NACIONES UNidAs (1997): Migración y desarrollo. Sección reproducción Naciones Unidas, pág. 65.

- (1999): Recomendaciones sobre estadisticas de las migraciones internacionales. Ed. Sección reproducción Naciones Unidas, pág. 91.

Palmer, R.; Colton, J. (1981): Historia Contemporánea. Ed. Akal/textos, Madrid, pág. 848.

PolANyi, K. (1992): La gran transformación. Ed. Fondo de Cultura Económica, México, pág. 306.

SMith, A. (1999): La riqueza de las naciones. Libros I-If-Ill y selección de los libros IV y V. Ed. Alianza, Madrid, pág. 818.

Soros, G. (1999): La crisis del capitalismo global. Ed. Debate, Madrid, pág. 277

StANISLAW, J. y YERGIN, D. (2000): Pioneros y lideres de la globalización. Ed. Javier Vergara, Buenos Aires, pág. 655.

VELTZ, P. (1999): Mundialización, ciudades y territorios. Ed. Ariel, Barcelona, pág. 255. 